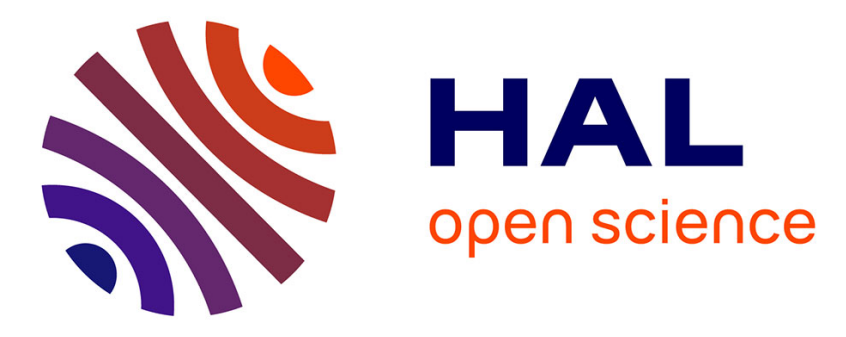

\title{
Pyridine assisted desilication of mordenite
}

Hussein Issa, Joumana Toufaily, Tayssir Hamieh, Alexander Sachse, Ludovic

Pinard

\section{To cite this version:}

Hussein Issa, Joumana Toufaily, Tayssir Hamieh, Alexander Sachse, Ludovic Pinard. Pyridine assisted desilication of mordenite. Applied Catalysis A: General, 2019, 583, pp.117139. 10.1016/j.apcata.2019.117139 . hal-02352213

\section{HAL Id: hal-02352213 https://hal.science/hal-02352213}

Submitted on 6 Nov 2019

HAL is a multi-disciplinary open access archive for the deposit and dissemination of scientific research documents, whether they are published or not. The documents may come from teaching and research institutions in France or abroad, or from public or private research centers.
L'archive ouverte pluridisciplinaire HAL, est destinée au dépôt et à la diffusion de documents scientifiques de niveau recherche, publiés ou non, émanant des établissements d'enseignement et de recherche français ou étrangers, des laboratoires publics ou privés. 


\title{
Pyridine assisted desilication of mordenite
}

\author{
Hussein Issa, ${ }^{1}$ Joumana Toufaily, ${ }^{2}$ Tayssir Hamieh, ${ }^{2}$ Alexander Sachse, ${ }^{1 *}$ Ludovic Pinard ${ }^{1 *}$ \\ ${ }^{1}$ Institut de Chimie des Milieux et Matériaux de Poitiers (IC2MP) - UMR 7285 CNRS, UFR SFA, Bât. \\ B27, 4 rue Michel Brunet, TSA 51106, 86073 Poitiers Cedex 9 (France) \\ ${ }^{2}$ Université Libanaise, Laboratoire des matériaux, catalyse, environnement et méthodes analytiques
} (MCEMA), Hadath, Libanon

Corresponding authors: ludovic.pinard@univ-poitiers.fr, alexander.sachse@univ-poitiers.fr

\begin{abstract}
Pyridine assisted alkaline desilication has been elaborated as new post-synthetic modification strategy of mordenite. The addition of pyridine during the desilication treatment revealed to impact materials properties through a dual action on textural and chemical properties; substantially different in comparison to the classical alkaline treatment or CTAB assisted desilication. As far as texture is concerned the use of pyridine permits to greatly modify the desilication scheme, hence yielding aggregates of smaller zeolite particles with substantially higher amount of external silanols. The presence of pyridine in the as-synthesized mordenites allows to in situ generate extra-framework aluminium (EFAL) species during final calcination step. Both of these features, smaller particle size and the presence of EFAL species improve catalytic properties considerably. Whilst the achievement of smaller particles reduces diffusion path length, the presence of EFAL species allow for exalting acidity and hence catalytic activity in $n$-hexane cracking and propene transformation.
\end{abstract}

Keywords: zeolites, desilication, pyridine, mordenite, Brønsted acid sites, aluminium extraframework species 


\section{Introduction}

Mordenite is one of the big five zeolites and finds extensive industrial application particularly in the petrochemistry.[1] The mordenite structure features one-dimensional 12-membered rings $(\mathrm{MR})(6.7 \times 7.0 \AA)$ that are connected to one 8 -MR channel $(2.6 \times 5.7 \AA)$ in the crystallographic $c$ direction and one 8-MR (3.4 $\mathrm{\AA}$ x $4.8 \AA$ ) side pocket in the $b$ direction.[2] In most heterogeneous catalytic processes in which mordenite is used the acid sites within the 12-MR are the sole active sites, as most reactants are sterically hindered to access Brønsted acid sites (BAS) located in the 8-MR. Hence, mordenite can be described as featuring a pseudo one-dimensional pore structure with single file diffusion. It has yet been proven that in certain application acid sites in the 8-MRs are the catalytic active. Indeed, Bahn et al.[3] concluded that the active site for carbonylation of dimethyl ether to methyl acetate are exclusively those within the 8-MR side pockets. Veefkind et. al.[4] proposed that the monoethyl amine intermediate resulting of the reaction of ethanol with ammoniac, is selectively stabilized by the 8 MRs. Moreover, Gounder et al.[5] showed that monomolecular cracking and dehydrogenation turnovers occur quasi selectively in the 8-MR side pockets. In a very recent paper,[6] we evidenced that it is the acid sites located in the 8-MR side pockets prove active for the toluene disproportionation and that for the $n$-hexane cracking the Brønsted acid sites in 12-MR channels and 8-MRs side pockets both catalyze the reaction. Indeed, for the $n$-hexane cracking the constrained acid sites (i.e. those located in the 8-MRs) are 1.5 times more active than the unconstrained (i.e. those located in the 12-MRs). The structural nature of the side pockets is extremely prone to rapid deactivation due to pore blocking. Even one coke molecule at the entrance of the pore aperture of a 12-MR channel disables all the active sites located in the side pockets and of the channel. Coke is hence extremely toxic for mordenite [7-8]. 
Throughout the past 20 years important achievements were reached in the quest for mitigating coke formation by reduction of the diffusion path length.[9] Two main approaches have been developed, which are: (i) the development of nano-sized zeolites (reduction of diffusion path length through minimizing crystal size) and (ii) development of zeolites with intracrystalline mesoporosity (reduction of diffusion path length through the creation of structural "shortcuts"). Numerous of strategies based on these concepts have been disclosed and have been resumed in various excellent review articles.[10-13] Among zeolite hierarchization strategies the by far most attractive is based on desilication, due to its simplicity and cost efficiency.[14] During the desilication process molecular silica species are removed from the zeolite structure, which allows to form inner cavities of mesoporous sizes.

Desilication of mordenite in alkaline solutions has been described in a number of contributions and allows for improving catalytic efficiency in the liquid phase alkylation of benzene,[14,15] oligomerization of pentene,[16] transformation of $m$-xylene,[17] and in the pyrolysis of lignocellulosic biomass.[18]

Mordenite desilication in the presence of CTAB has been extensively described by Ivanova and co-workers.[19-21] Here the presence of the surfactants allows for a reprecipitation of the dissolved silica around surfactant micelles yielding a mesoporous MCM-41 like phase, which feature catalytically active zeolite fragments in the mesopore walls. This strategy was coined as recrystallization.

The use of amines, such as piperidine and hexamethylenediamine during alkaline zeolite treatment has recently been described for ZSM-5 by Wang et al.[22] The authors observed that the use of theses additives has an important effect on the zeolite structure. Indeed, it was inferred that the use of such diamines protects the zeolite from uncontrolled desilication, allowing thus the formation of controlled mesoporosity and reducing the loss of microporosity during the alkaline treatment. A similar behavior has been observed for the ZSM-5 
desilication through the use of quaternary ammonia salts, such as tetramethylammonium, during alkaline treatment.[13]

In this contribution we present the pyridine assisted desilication of mordenite. To the best of our knowledge this is the first report that describes the use of pyridine during alkaline treatment of zeolites. The idea behind this approach was to selectively protect the active sites in the zeolites during the basic attack of the framework. Through comparison with samples achieved through classical alkaline treatments and CTAB assisted desilication, it was deduced that the use of pyridine allows for generating aggregates of very small zeolite crystals. The samples obtained through pyridine assisted desilication allow for observing superior activities and stabilities in several model reactions, such as the monomolecular $n$-hexane cracking, the toluene disproportionation and the transformation of propene to coke.

\section{Experimental Section}

\subsection{Materials and Methods}

Four series of catalyst (D, DC, DP and DPc) were prepared from a commercial protonic mordenite (M20; Süd Chemie). Table 1 summarizes the operating conditions used for the post-treatments and obtained yields.

The $\mathrm{D}_{\mathrm{x}}$ series corresponds to a regular desilication by $\mathrm{NaOH}$ with 0.2 or $0.6 \mathrm{M}$ at $85{ }^{\circ} \mathrm{C}$ for $1 \mathrm{~h}$ (the subscript $\mathrm{x}$ indicates the concentration) und stirring. The DC samples have been prepared through desilication in presence of hexadecyltrimethylammonium bromide (CTAB, $0.27 \mathrm{M})$. DP and DPc samples are obtained through the alkaline treatment assisted by pyridine. The pyridine is either added in excess to the basic solution (DP series), or previously chemisorbed on M20 (DPc). The amount of pyridine added to the alkaline solution were 1650,8250 and $16500 \mu \mathrm{mol} \mathrm{g} \mathrm{g}^{-1}$, which correspond to ca 3, 15 and 30 times the number of Brønsted acid sites probed on M20 by pyridine at $150{ }^{\circ} \mathrm{C}$. The chemisorption of pyridine was 
carried out in a fixed bed reactor at $150{ }^{\circ} \mathrm{C}$ with a nitrogen gas flow saturated in pyridine for $1 \mathrm{~h}$. After $1 \mathrm{~h}$ of stripping under nitrogen in order to remove physisorbed species, the number of pyridine chemisorbed was measured and amounts to $550 \mu \mathrm{mol} \mathrm{g}^{-1}$. For all of the treatments, reactions were quenched in an ice bath followed by a mild acid leaching through the adding a few drops of concentrated $\mathrm{HCl}(6 \mathrm{M})$ and stirring at room temperature for $1 \mathrm{~h}$. The catalysts were recovered by centrifugation, washed with deionized water, dried and calcined at $550{ }^{\circ} \mathrm{C}$ for $4 \mathrm{~h}$ (heating rate $5{ }^{\circ} \mathrm{C} \min ^{-1}$ ). The protonic form of the catalyst was obtained after three consecutive exchanges with a $1 \mathrm{M}$ solution of $\mathrm{NH}_{4} \mathrm{NO}_{3}$ using the proportion of $50 \mathrm{~cm}^{3} \mathrm{~g}^{-1}$ of zeolite. The exchange was carried out at $85{ }^{\circ} \mathrm{C}$ for $1 \mathrm{~h}$. After a careful wash up to $\mathrm{pH} 7$ the solids were dried at $80{ }^{\circ} \mathrm{C}$ during $12 \mathrm{~h}$ and then calcined $550{ }^{\circ} \mathrm{C}$ for $4 \mathrm{~h}$.

The samples P8250 and P550, were obtained through blank treatments, and correspond to treatments in which the alkaline treatment was suppressed.

\subsection{Characterization techniques}

X-ray diffraction (XRD) patterns were acquired on a D5005 BRUKER AXS diffractometer over a $5^{\circ}-40^{\circ} 2 \theta$ range using the $\mathrm{CuK}_{\alpha}$ radiation $(\lambda=1.541874 \AA)$. Coherent crystallite size and lattice strain were calculated by the Willamson-Hall (E1) relation:[23]

$$
\beta_{h k l} \cos \theta=\frac{K \lambda}{D}+4 \varepsilon \sin \theta
$$

where $\beta_{h k l}$ is the full width of half maximum (FWHM), $K$ stands for the shape factor (0.9), $\lambda$ represents the wavelength of $\mathrm{CuK}_{\alpha}$ radiation $(1.541874 \AA$ ), D is the coherent crystalline size and $\varepsilon$ gives the crystal strain. The morphology of the parent and treated samples was monitored by a transmission electronic microscopy (TEM) using Philips CM 120 microscope that equipped with $\mathrm{a} \mathrm{LaB}_{6}$ filament. The nitrogen sorption measurement was determined by a Micromeritics 3FLEX. Before any measurement, each sample (50-60 mg) was out-gassed at 
$350{ }^{\circ} \mathrm{C}$ for $12 \mathrm{~h}$. Sorption measurements were performed at $-196{ }^{\circ} \mathrm{C}$. The total pore volume was determined from the $\mathrm{N}_{2}$ adsorbed volume at $\mathrm{p} / \mathrm{p}_{0}=0.96$ and the $t$-plot method was used to calculate the microporous volume. Mesopores size distribution was estimated by the BJH method. Chemical composition of the samples was measured by using an Inductively Coupled Plasma-Atomic Emission Spectroscopy (ICP -AES) on a Perkin Elmer Optima 2000 DV apparatus. The nature, concentration and strength of acidity were studied by using pyridine as a probe molecule followed by infrared spectroscopy (FTIR) through a Nicolet 5700 apparatus with $2 \mathrm{~cm}^{-1}$ optical resolution. Before analysis, the catalyst was pressed ( 0.5 ton) into a selfsupporting wafer $\left(2 \mathrm{~cm}^{2}, 10-30 \mathrm{mg}\right)$ and pretreated from $20{ }^{\circ} \mathrm{C}$ to $450{ }^{\circ} \mathrm{C}$ under air flow $\left(60 \mathrm{~cm}^{3} \mathrm{~min}^{-1}\right)$. The sample was then out-gassed $\left(10^{-5} \mathrm{bar}\right)$ during $1 \mathrm{~h}$ at $200{ }^{\circ} \mathrm{C}$, after which finally an IR spectrum was taken. Then, the sample was cooled to $150{ }^{\circ} \mathrm{C}$ and exposed to 1.5 mbar pyridine pressure during $5 \mathrm{~min}$ and then outgassed $\left(10^{-5} \mathrm{bar}\right)$ in order to eliminate the physisorbed pyridine. The adsorption of pyridine at $150{ }^{\circ} \mathrm{C}$ and $450^{\circ} \mathrm{C}$ measures the amount of Brønsted and Lewis acid sites by integrating the band areas at 1545 and $1454 \mathrm{~cm}^{-1}$, respectively and using the following extinction coefficients measured at $293 \mathrm{~K}: \varepsilon_{1545}=1.13$ and $\varepsilon_{1454}=1.28 \mathrm{~cm} \mathrm{~mol}^{-1}$.

\subsection{Characterization of acidic properties of hierarchical zeolites}

The $n$-Hexane cracking (CC) was performed to quantify the number and evaluate the strength of active sites [24]. The transformation of propene (C) was used to estimate the resistance to coking. The Table 2 reports the operating conditions for the two model reactions. $n$-Hexane cracking was carried out in a fixed-bed microreactor under plug flow conditions, whilst coking through propene transformation was performed in a microbalance. The samples with a particle size between 0.2 and $0.4 \mathrm{~mm}$ were pretreated at the reaction temperatures of coking, 
and cracking, i.e. $350{ }^{\circ} \mathrm{C}$ and $540{ }^{\circ} \mathrm{C}$ respectively, under primary vacuum for the first and under nitrogen flow for the other one. For the reaction in a fixed bed reactor, reaction products were sampled during $1 \mathrm{~h}$ in a 10 port-valve, then analyzed by gas chromatography (GC) equipped with a Flame Ionization Detector (FID). A $50 \mathrm{~m} \mathrm{Cp}-\mathrm{Al}_{2} \mathrm{O}_{3} / \mathrm{Na}_{2} \mathrm{SO}_{4}$ capillary column of $0.32 \mathrm{~mm}$ internal diameter was used for the $n$-hexane cracking.

\section{Results and discussion}

\subsection{Textural properties}

Pyridine assisted desilication was carried out by following two approaches: $(i)$ the addition of pyridine during desilication (DP series) and (ii) the pre-adsorption of pyridine through chemisorption by interacting with the BAS of the zeolite prior to desilication ( $\mathrm{DP}_{\mathrm{c}}$ series). It is to note that the concentration of $\mathrm{NaOH}$ was kept constant for each experiment $(0.6 \mathrm{M})$. The textural, chemical and catalytic properties of the modified zeolites were compared with the parent mordenite (Tables 3-4). Samples were further compared to blank experiments, in which no pyridine was added (D series), CTAB was added (DC series) or in which no $\mathrm{NaOH}$ was used (P series).

The nitrogen adsorption and desorption isotherms at $77 \mathrm{~K}$ of the parent mordenite is of type I, which is expected for a purely microporous material (Figure 1) and features a microporous volume of $0.18 \mathrm{~cm}^{3} \mathrm{~g}^{-1}$. The morphology of the sample consists out of aggregates of crystals $(50-100 \mathrm{~nm})$ that are probably due to the steaming process applied during the preparation of this sample by the supplier (Figure 2).

First classical desilication using aqueous $\mathrm{NaOH}$ was studied on the parent MOR. Here for $\mathrm{NaOH}$ solutions of various concentrations ranging from 0.2 to $0.6 \mathrm{M}$ were tested and abbreviated by $\mathrm{D}_{0.2}$ and $\mathrm{D}_{0.6}$. An important part of the zeolite dissolves during the alkaline treatment, and the higher the concentration of the base, the lower the materials yield (Table 
1). As can be inferred from the nitrogen adsorption and desorption isotherm, the treatment using the $0.2 \mathrm{M}$ solution hardly impacts the shape of the isotherm, which indicates that no textural modification were developed during the treatment (Figure 1). This finding was further confirmed by the electron microscopy images, which present identical textural features compared to the parent mordenite (Figure 2). The isotherm of the desilicated mordenite achieved through a treatment with a $0.6 \mathrm{M} \mathrm{NaOH}$ solution is of type IV and presents an important gas uptake in the high relative pressure region $\left(\mathrm{p} / \mathrm{p}_{0}>0.5\right)$ and features an $\mathrm{H} 3$ hysteresis loop, which is characteristic for a large size distribution of mesopores (Figure S1). During the treatment microporosity was affected and reduced to $0.09 \mathrm{~cm}^{3} \mathrm{~g}^{-1}$ (Table 3). Indeed, the micrographs of this sample present electron clear regions within the mordenite crystals, which allows to conclude the formation of mesopores of a wide size distribution

\section{(Figure 2 and S1).}

With the aim to preserve the acidity of the parent mordenite during the desilication step, a pyridine pre-adsorption on M20 was performed, followed by a temperature treatment at $150{ }^{\circ} \mathrm{C}$ in order to remove eventually physisorbed pyridine. The amount of chemisorbed pyridine by this strategy was quantified through thermogravimetric analysis (TGA) and amounts to $550 \mu \mathrm{mol} \mathrm{g}$ zeolite. The pyridine pre-adsorbed sample was then subjected to alkaline treatment using a $0.6 \mathrm{M}$ aqueous $\mathrm{NaOH}$ solution. The presence of chemisorbed pyridine has only little impact on the synthesis yield (Table 1). In addition, pyridine remains adsorbed within the sample throughout the alkaline treatment, as revealed by TGA (Figure S2). It is interesting to notice that the shape of the isotherm of this sample is similar to the one obtained by usual desilication yet featuring the striking difference of a sharp uptake in the very high relative pressure region close to saturation and achieving a mesoporous volume of $0.66 \mathrm{~cm}^{3} \mathrm{~g}^{-1}$ (Figure 1). The difference in texture was further inferred from the TEM images, which allow to observe next to the development of intracrystalline mesoporosity smaller 
particles of sizes below $10 \mathrm{~nm}$ that feature zeolite crystallinity (Figure 2). Indeed, the important nitrogen uptake at very high relative pressures is characteristic for the condensation in interparticular porosity.[25] Interestingly, merely a minor reduction of the FWHM of the XRD peaks is observed, and coherent crystal sizes obtained through applying Willamson-Hall analysis are of 66 and $48 \mathrm{~nm}$ for M20 and chemisorbed pyridine assisted mordenite desilication $\left(\mathrm{DP}_{550}\right)$, respectively (Table 3). Yet, the intensity of the XRD peaks importantly decreases, indicating the reduction of diffraction efficiency (Figure S3). It can hence be assumed that the small size of the zeolite particles contain insufficient diffraction planes to allow for the observation of XRD peaks, which explains the important reduction of crystallinity.[26]

Though the developed pyridine pre-adsorption strategy followed by alkaline treatment allows for importantly impacting the textural properties it features as major drawback the limitation of the maximal pyridine content to its chemisorption capacity. In order to further increase the amount of pyridine during alkaline treatment, an excess of pyridine with respect to the number of acid sites was added directly to the aqueous $\mathrm{NaOH}$ solution, i.e. an excess of 3,15 and 30 times the amount of pyridine compared to the BAS. From the nitrogen physisorption of the obtained samples important differences in the textural properties of the achieved materials can be deduced (Figure 1). The sample achieved with the lowest amount of pyridine $\left(\mathbf{D}_{\mathbf{0 . 6}} \mathbf{P}_{\mathbf{1 6 5 0}}\right.$, Table 1) features an isotherm that is very similar to the one of the sample achieved by the pyridine pre-adsorption strategy with comparable microporous and mesoporous volume. Additionally, from the TEM images very similar morphological features can be observed (Figure 2), which indicates that the direct addition of pyridine to the desilication solution has a similar effect as pre-adsorption of pyridine. Increasing the amount of pyridine in the desilication solution has important implications as far as texture is concerned as can be observed from the nitrogen adsorption isotherms. Indeed for the sample treated with the 
highest amount of pyridine $\left(\mathbf{D}_{\mathbf{0 . 6}} \mathbf{P}_{\mathbf{1 6 5 0 0}}\right.$, Table $\left.\mathbf{1}\right)$ the shape of the isotherm has completely changed and merely the sharp uptake at very high relative pressure is observed, which indicates the absence of intracrystalline mesoporosity. This is confirmed by the TEM images for which a much greater part of smaller aggregated particles can be observed (Figure 2). This is further indicated form the overall crystallinity (Table 3, and Figure S3) that reduces substantially for samples with increasing amount of pyridine in the synthesis mixture.

In order to size the impact of pyridine during the alkaline treatment a blank experiment was conducted in which the parent zeolite was added to an aqueous solution that merely contained $8250 \mu \mathrm{mol} \mathrm{g}$ zeolite of pyridine $\left(\mathbf{P}_{\mathbf{8 2 5 0}}\right.$, Table $\left.\mathbf{1}\right)$. The achieved sample presents textural properties similar to the parent zeolite, the only difference is the microporous volume that is slightly reduced, which indicates that the microporosity might be partially blocked (see part $3.2)$.

For the sake of comparison, desilication was carried out in the presence of CTAB (DC series, Table 1). In earlier works it has been described that depending on the synthesis conditions the addition of quaternary amines can lead to the protection of zeolites from extensive desilication and, through applying harsher conditions to the recrystallization of mordenite.[14-16] For the applied synthesis conditions recrystallisation into an amorphous mesoporous phase can be observed by TEM (Figure 2), yet the overall amount of recrystallized material is very low as indicated by the absence of capillary condensation in the $\mathrm{N}_{2}$ adsorption isotherm at $\mathrm{p} / \mathrm{p}_{0}$ between 0.4 and 0.5 (Figure 1).

\subsection{Chemical properties}

Figure 3 compares the hydroxyl stretching vibration of IR spectra before and after adsorption of pyridine at $150{ }^{\circ} \mathrm{C}$, on all catalysts. M20 exhibits a band at $3607 \mathrm{~cm}^{-1}$, which is assigned to the bridged hydroxyl groups (SiOHAl). The less intense bands at 3745,3733 and $3684 \mathrm{~cm}^{-1}$ 
are due to stretching vibrations of external and internal silanols $\mathrm{Si}-\mathrm{OH}$, and $\mathrm{OH}$ linked to extraframework aluminum species (EFAL), respectively. The broad band centered at $3503 \mathrm{~cm}^{-1}$, it related to the presence of hydroxyl nests.[27] The presence of hydroxyl nests in the parent zeolite can be explained according to what was described by Barrer and Maki.[28] They observed that the calcination of a zeolite in its ammonium form, leads to the dislodgment of aluminum atoms, leaving four $\mathrm{OH}$ groups saturating the four $\mathrm{Si}$ atoms previously connected to the aluminum. The developed hydroxyl nests are stabilized by a network of hydrogen atoms, in which each $\mathrm{Si}-\mathrm{OH}$ group is bonded via a hydrogen bond to an oxygen atom of a neighboring $\mathrm{OH}$ group, which leads to a broad band centered at ca. $3500 \mathrm{~cm}^{-1}$.

The chemisorption of pyridine at $150{ }^{\circ} \mathrm{C}$ only leads to the disappearance of the band at $3607 \mathrm{~cm}^{-1}$, therefore all the bridged hydroxyl groups are accessible to probe molecule which means they are located in the 12-MR membered rings (MR) channels and/or to the intersection between the side pocket constituted of 8-MR and 12- MR channels. It is worth to mention that mordenites featuring a lower $\mathrm{Si} / \mathrm{Al}$ ratio present $\mathrm{BAS}$ at the bottom of site pockets, which are inaccessible to pyridine.[6] The number of acid sites $\left(C_{B}\right)$ probed by pyridine is $552 \mu \mathrm{mol} \mathrm{g}^{-1}$ (Table 4), while the theoretical value calculated assuming that all aluminum is in the framework would amount to $650 \mu \mathrm{mol} \mathrm{g}^{-1}$. The observed difference is due to the presence of EFAL species, which is confirmed by the presence of Lewis acid sites $\left(\mathrm{C}_{\mathrm{L}}=\right.$ $47 \mu \mathrm{mol} \mathrm{g}{ }^{-1}$, Table 4). Indeed, the sum of $C_{B}$ and 2 times $C_{L}$ (assuming that EFAL are of the general formula $\mathrm{Al}_{2} \mathrm{O}_{3}$ ), corresponds to the value of the theoretical acidity. As a result, we can thus deduce that $15 \%$ of the aluminum in M20 is present under the form of extra-framework species. It is to note that the presence of EFAL species does yet not prevent the access of the organic probe molecule to the acid sites. The dislodged $\mathrm{Al}$ atoms remain within the micropores/mesopores in the form of cationic $\left(\mathrm{Al}^{3+}, \mathrm{AlO}^{+}\right)$, neutral or charged species, which 
can further feature a certain degree of polymerized, or be in the form of hydroxylaluminates (e.g. $\left.\mathrm{Al}(\mathrm{OH})^{2+}, \mathrm{Al}(\mathrm{OH})^{+}, \mathrm{AlOOH}, \mathrm{Al}(\mathrm{OH})_{3}\right)[29-31]$.

On the samples obtained through classical desilication (D series), increasing the alkaline concentration leads to the reduction of the intensity of band related to hydroxyls nest $\left(3503 \mathrm{~cm}^{-1}\right)$ up to its complete disappearance, and concomitantly to the increase of external silanols (band at $3745 \mathrm{~cm}^{-1}$ ). This hence indicates that silicon extraction takes place at defective sites within the crystal (i.e. hydroxyl nests). This has previously been demonstrated for USY and H-ZSM-5 desilication by Quin et al.[32] and Holm et al.[33], respectively (Scheme 1).

After a slight decrease in the bridged hydroxyl band $\left(3607 \mathrm{~cm}^{-1}\right)$, its intensity remains stable; yet the accessibility of the acid sites decreases importantly. For the $\mathrm{D}_{0.6}$ sample merely $2 / 3$ of acid sites are accessible to pyridine, which is most likely due to incomplete removal of extraframework silicon (EFSI) or aluminum (EFAL) species during the mild acid leaching process and which are trapped within the zeolite porosity. These extra-framework species are most probably located at the entrance of the pore mouths, which blocks the pore access even to nitrogen (reduction of microporous volume, Table 3) and hence to a part of the BAS located within the channels, which reduces to $324 \mu \mathrm{mol} \mathrm{g}^{-1}$ for $\mathrm{D}_{0.6}$ (Table 4). Lutz et al [34, 35] detected on a modified FAU zeolite an important amount of AFSI species upon alkaline treatment or through combined acid-base treatments. Moreover, Stockenhuber and Lercher [36] evidenced EFSI species within dealuminated Y type zeolite. These silica rich species were located on the outside of the zeolite channels, whereas the EFAL/SI species have been proven to form long-range interaction with BAS.

The addition of CTAB during desilication presents almost no impact as far as acid site accessibility is concerned and similar BAS are observed as for the classical desilication. Hence, the presence of CTAB during the treatment does not modify the desilication process, 
contrariwise to that what has been observed for the addition of pyridine during the treatment (DP series). It should be mentioned that, in the absence of alkaline treatment (P series), the mere presence of pyridine causes, after calcination, significant changes in the number and nature of acid sites, without any significant modifications of silanol bands (Figure 3). Whatever the mode of introduction of pyridine though gas phase $\left(\mathrm{P}_{550}\right)$ or solution $\left(\mathrm{P}_{8250}\right)$, the number of BAS decreases by $35-40 \%$, while the amount of Lewis acid sites increases (171 and $86 \mu \mathrm{mol.g}{ }^{-1}$ for $\mathrm{P}_{8250}$ and $\mathrm{P}_{550}$, respectively). These changes can be ascribed to dealumination occurring during the calcination step in the presence of pyridine in the mordenite structure and chemisorbed on the BAS. The dealumination occurring during calcination of the zeolite containing pyridine is probably analogous to that of the ammonium form used for the ultra-stabilisation process of zeolite Y. This process developed by Mc Daniel and Maher in the late 1970's [37] consists of two major steps: (i) a nearly complete exchanged of sodium ions by ammonium and (ii) thermal treatment to temperatures higher than $800{ }^{\circ} \mathrm{C}$. The in this way performed thermal deamination allows for partial dealumination of the zeolite and to the formation of EFAL. Therefore, we can assume that the calcination of the chemisorbed pyridine leads then to a selective dealumination process. As such, the total acidity $\left(C_{B}+2 C_{L}=680 \mu \mathrm{mol} \mathrm{g}-1\right)$ of $P_{8250}$ corresponds to that of the parent zeolite (Table 4), which means that the extra-framework species created during the pyridine combustion do not affect the accessibility to BAS. We can assume that EFAL species are trapped in the side pockets (a location on the outer surface is less likely, due to a need of a migration step). On $\mathrm{P}_{550}$, the total acidity $\left(540 \mu \mathrm{mol} \mathrm{g}{ }^{-1}\right)$ is slight lower than that of M20.

The most striking difference in the pyridine assisted desilication of mordenite is the important formation of non-acidic external silanol groups $\left(3745 \mathrm{~cm}^{-1}\right.$, Figure 3). Moreover, the intensity of this band increases with increasing concentration of pyridine used in the desilication solution. The number of BAS is almost equivalent to the blank samples (P series) achieved in 
the absence of alkaline treatment, hence indicating that the loss of BAS results from the combustion of pyridine during the calcination step. This further suggests that pyridine truly protects BAS during that alkaline desilication step. It indeed seems that the presence of pyridine allows for orienting the hydrolysis of the $\mathrm{Si}-\mathrm{O}-\mathrm{Si}$ bond by protecting aluminum species through filling of the $12 \mathrm{MR}$ channels. Hence the action range of hydroxides $\left(\mathrm{HO}^{-}\right)$is restricted and through increasing the amount of pyridine the attack on external surface is favored (Scheme 1). This confirms well to the observed morphology of the pyridine assisted desilicated samples (Figure 2).

\section{Catalytic performances}

\section{1. n-Hexane cracking}

$n$-Hexane cracking was chosen to characterize the impact of the presence of pyridine during the alkaline treatment. Figure 4 compares the conversion of achieved catalysts as a function of the time-on-stream. Though the zeolite framework is considered as "monodimensional" almost no deactivation of the parent catalyst (M20) is observed, the loss of activity is only of 14\% (Table 5). The coke content is very low $(0.5 \mathrm{wt} . \%$, Table 5) even after $1 \mathrm{~h}$ of reaction, which indicates a low partial pressure of olefins. The cracking mechanism which occurs through the applied operating conditions $\left(540{ }^{\circ} \mathrm{C}, \mathrm{P}_{\mathrm{n}-\mathrm{C} 6}=0.01 \mathrm{MPa}\right)$ is hence monomolecular. The $\mathrm{C}_{3}$ cracking product is largely predominant $\$$ whilst $\mathrm{C}_{1}, \mathrm{C}_{2}, \mathrm{C}_{4}$ and $\mathrm{C}_{5}$ products (Figure S4) are formed in small amount with a $\mathrm{C}_{4} / \mathrm{C}_{2}$ molar ratio close to 1 and a $\mathrm{C}_{5} / \mathrm{C}_{1}$ molar ratio of 0.7, indicating the occurrence of secondary cracking (Figure S5). For each cracked molecule one alkane and one alkene are formed $(\mathrm{O} / \mathrm{P} \approx 1$, Table 5$)$. The distribution of cracking products confirms that the cracking mechanism involves a penta-coordinated carbonium ions, i.e. occurrence of a monomolecular mechanism. Isomerization of $n$-hexane occurs before monomolecular cracking as indicated by an isomer to linear hydrocarbons molar ratio $(\mathrm{i} / n)$ of 
1.35 (Table 5). The turnover rate of BAS (TOF) of the parent zeolite is ca $130 \mathrm{~h}^{-1}$, which corresponds to that calculated for the TOF in 12-MR channels of mordenite with a $\mathrm{Si} / \mathrm{Al}$ ratio of 10.[6] The samples achieved through alkaline treatment with or without the presence of CTAB promotes slightly the branched products $(\mathrm{i} / n$ of ca 1.6$)$ the formation of olefin $(\mathrm{O} / \mathrm{P}$ between 1.3-1.5, Table 5), probably by dehydrogenation reaction $\left(\mathrm{H}_{2}\right.$ is not detected), which favors the coke formation and thus the catalyst deactivation. The losses of activity ranges from 39 to $65 \%$ (Table 5). Indeed, the deactivation on mordenite zeolite occurs by pore blocking [7-8], which means that a low coke content is enough to completely deactivate the catalyst. The deactivation remains nevertheless limited given the very low coke content (3.25.2 wt.\%). After alkaline treatment, TOF values are higher than on the parent zeolite. It is worth to mention that TOF are calculated from the number of acid sites probed by pyridine, yet as discussed before, after the desilication treatment only one part of BAS is accessible to pyridine (approximately $2 / 3$ ). The inaccessibility of pyridine to BAS does yet not mean that they are inaccessible to $n$-hexane, which features a smaller kinetic diameter. The TOF were hence recalculated taking into account the accessibility of BAS (i.e. those probed by pyridine), therefore the values are decreased and closer to the one obtained on the parent zeolite.

The slight dealumination occurring during the calcination of pyridine on $\mathrm{P}_{550}$ and $\mathrm{P}_{8250}$ samples is sufficient to improve the catalyst activity by doubling the TOF of protonic sites (Table 5). The activity on $\mathrm{D}_{0.6} \mathrm{P}_{1650}$ is the same even at lower conversion obtained by decreasing the contact time (Figure S6). This means that a kinetic order of 1 for the cracking of $n$-hexane, which agrees with a monomolecular mechanism. The increase in activity of the protonic sites can be related to the presence of EFAL species by an inductive effect on the hydroxyl groups.[38] Moreover, high O/P molar ratios (1.5-1.7) could be related to hydride abstraction induced by Lewis acid sites.[39-40] Yet, the presence of these "super-acid" sites 
has been contested by Iglesia and co-workers,[41] who suggested that the apparent increased BAS strength would not result from electronic interactions with EFAL species, but rather from a higher solvation effect of the zeolite voids attributable to the occlusion of the void space by extra-framework $\mathrm{Al}$ residues. This reasoning is questionable through comparing the TOF values of $n$-hexane cracking obtained by MFI (i.e. $350 \mathrm{~h}^{-1}$, [42]) and MOR zeolites, which are present identical void size. The pyridine pre-adsorption followed by alkaline treatment allows a huge improvement of the catalyst activity (by 2-3 times) and in TOF (4-5 times), (Table 5). As the initial conversion is higher (> 30\%), a higher amount of olefins are

formed, which lead to catalyst deactivation (Figure 4). Yet, the coke content remains limited (1.7-2.8 wt $\%$ ) in spite of large amount of external silanol and featuring $\mathrm{C}_{1}, \mathrm{C}_{2}, \mathrm{C}_{3}$ as main cracking product (monomolecular mechanism) and $\mathrm{C}_{4}$ and $\mathrm{C}_{5}$ (mainly branched products, Table 5) are still formed in strictly parallel reactions (Figure S4-a). A low coke content as well as monomolecular mechanism implies a fast diffusion of olefins, thanks to the improved textural properties generated during of alkaline treatment of pyridine pre-absorbed samples. Thus, the presence of EFAL species combined with shortening of the diffusion path length allows to improve both the catalyst activity and stability. Despite significant deactivation of more than $50 \%$ (Table 5), the catalysts $\mathrm{DP}_{550}$ and $\mathrm{D}_{0.6} \mathrm{P}_{1650}$ are still more active than the parent zeolite.

\subsection{Coke formation}

The impact of alkaline treatment in the presence or absence of pyridine on coke formation was determined through the mass uptake during the transformation of propene at $350{ }^{\circ} \mathrm{C}$. (Table 6). On the parent zeolite, the coke uptake increases rapidly and reaches 8 wt.\% after 
$2 \mathrm{~h}$ (Figure 5). Despite the decrease in acidity after desilication, the initial coking rate (derivative of the coke uptake curve) is twice as high. The higher coking rate can be ascribed to an increase in strength of the protonic sites due to their interaction with the Lewis acid EFAL species. Indeed, the effect of acidity on the rate of propene transformation into coke was determined at $350{ }^{\circ} \mathrm{C}$ over a series of $\operatorname{HFAU}(\mathrm{Y})$ zeolites with different framework $\mathrm{Si} / \mathrm{Al}$ ratios.[43] For dealuminated samples (Si/Al from 16 to 100) the coking rate was roughly proportional to the concentration of the protonic sites, which can be related to the similarity in strength of the isolated sites of these zeolites. The slightly greater TOF value found for the most dealuminated sample was ascribed to an increase in strength of its protonic sites due to their interaction with Lewis acid EFAL species. As far as the amount of coke uptake after $10 \mathrm{~h}$ is concerned, it depends rather on the textural properties of the achieved materials. The presence of mesopores (Table 3) favor the accumulation (and retention) of carbonaceous compounds.[25, 44, 45]

\section{Conclusion}

In this work we have proven that adding pyridine during alkaline treatment importantly modifies the classical desilication scheme. Pyridine allows to direct the desilication of mordenites, through its interaction with external hydroxides, which amount increases important by increasing the portion of pyridine during treatment. This hence allows to selectively direct desilication towards the achievement of small zeolite particles, which diffraction efficiency is insufficient to be detected by XRD. Pyridine remains present in the zeolite structure throughout the treatment and hence in the as-synthetized materials. During the calcination step the decomposition of the amine leads to dealumination and hence to the formation of internal EFAL. It has been found that both of these features importantly impact 
of the catalytic properties in $n$-hexane cracking and in the propene transformation. Whilst the reduction of the particle size allows for reducing diffusion path length the presence of EFAL leads to an exaltation of acidity yielding to superior activities in all of the studied reactions.

\section{Acknowledgments}

Hussein Issa thanks Islamic Center Association for guidance and higher education for the financial support of his doctoral studies. The authors acknowledge financial support from the European Union (ERDF) and "Région Nouvelle Aquitaine".

\section{Reference}

[1] K. Tanabe, F. Hölderich, Appl. Catal. A. Gen. 181 (1999) 399-434.

[2] W. M. Meier, Kristallogr. Kristallgeom. Kristallphys. Kristallchem.115 (1961) 439450 .

[3] A. Bhan, A. D. Allian, G. J. Sunley, D. J. Law, A. Iglesia, J. Am. Chem. Soc. 129 (2007) 4919-4924.

[4] V. A. Veefkind, M. L. Smidt, J. A. Lercher, Appl. Catal. A 194-195 (2000) 319-332.

[5] R. Gounder, E. Iglesia, J. Am. Chem. Soc. 131 (2009) 1958-1971.

[6] H. Issa, J. Toufaily, T. Hamieh, J.- D. Comparot, A. Sachse, L. Pinard, in revision in Journal of Catalysis.

[7] N. Chaouati, A. Soualah, M. Chater, L. Pinard, J. Catal. 353 (2017) 28-36.

[8] N. Chaouati, A. Soualah, M. Chater, M. Tarighi, L. Pinard, J. Catal. 344 (2016) 354364.

[9] J. Pérez-Ramírez, C. H. Christensen, K. Egeblad, C. H. Christensen, J. C. Groen, Chem. Soc. Rev. 37 (2008) 2530-2542.

[10] D. P. Serrano, J. M. Escola, P. Pizarro, Chem. Soc. Rev. 42 (2013) 4004-4035.

[11] M. Hartmann, A. G. Machoke, W. Schwieger, Chem. Soc. Rev. 45 (2016) 3313-3330.

[12] K. Möller, T. Bein, Chem. Soc. Rev. 42 (2013) 3689-3707.

[13] A. Sachse, J. Garcia Martinez, Chem. Mater. 29 (2017) 3827-3853.

[14] R. Chal, C. Gérardin, M. Bulut, S. van Donk, Chem Cat Chem. 3 (2011) 67-81.

[15] J. C. Groen, T. Sano, J. A. Moulijn, J. Perez-Ramirez, J. Catal. 251 (2007) 21-27. 
[16] C. Bertrand-Drira X.-W. Cheng, T. Cacciaguerra, P. Trens, G. Melinte, O. Ersen, D. Minoux, A. Finiels, F. Fajula, C. Gerardin, Micro Meso Mater. 213 (2015) 142-149.

[17] N. Chaouati, A. Soualah, I. Hussein, J-D. Comparot, L. Pinard, Appl. Catal. A 256 (2016) 95-104.

[18] S. Stefanidis, K. Kalogiannis, E. F. Iliopoulou, A. A. Lappas, J. Martínez Triguero, M. T. Navarro, A. Chica, F. Rey, Green Chem. 15 (2013) 1647-1658.

[19] I. Ivanova, E. Knyazeva, Chem. Soc. Rev. 42 (2013) 3671-3688.

[20] I. Ivanova, A. Kasyanov, A. Maerle, V. I. Zaikovskii, Micro. Meso. Mater. 189 (2014) 163-172.

[21] I. A. Kasyanov, A. A. Maerle, I. I. Ivanova, V. I. Zaikovskii, J. Mater. Chem. A 2 (2014) 16978-16988.

[22] D. Wang, L. Zhang, L. Chen, H. Wu, P. Wu, J. Mater. Chem. A 3 (2015) 3511-3521.

[23] V. D. Mote, Y. Purushotham, BN. Dole, J. Theor. and Appl. Physics. 6 (2012) 1-8.

[24] M. Guisnet, L. Pinard, Catal. Rev. 60 (2018) 337-436.

[25] I. Batonneau-Gener, A. Sachse, J. Phys. Chem. C 123 (2019) 4235-4242.

[26] B. D. Hall, D. Zanchet D. Ugarte, J. Appl. Cryst. 33 (2000) 1335-1341.

[27] K. Yamagishi, S. Namba, T. Yashima, J. Phys. Chem., 95, 2 (1991) 872-877.

[28] R. M. Barrer, M.B. Maki, Can. J. Chem. 42 (1964) 1481-1487.

[29] M. -C Silaghi, C. Chizallet, P. Raybaud, Micro. Meso. Mater. 191 (2014) 82-96.

[30] D. L. Bhering, A. Ramirez-Solis, C. J. A. Mota, J. Phys. Chem. B. 107 (2003) 43424347.

[31] L. Kaluža, D. Gulková, Z. Vít, M. Zdražil, Fuel, 2013, 112, 272-276.

[32] Z. Qin, B. Shen, Z. Yu, F. Deng, L. Zhao, S. Zhou, D. Yuan, X. Gao, B. Wang, H. Zhao, H. Liu, J. Catal. 298 (2013) 102-111.

[33] M.S. Holm, S. Svelle, F. Joensen, P. Beato, C.H. Christensen, S. Bordiga, M. Bjørgen, Appl. Catal. A. 356 (2009) 23-30.

[34] W. Lutz, C.H. Rüscher, D. Heidemann, Micro. Meso. Mater. 55 (2002) 193-202.

[35] W. Lutz, R. Bertram, D. Heidemann, R. Kurzhals, C. Rüscher, G. Kryukosa, Z. Anorg. Allg. Chem. 637 (2011) 75-82.

[36] M. Stockenhuber, J. A. Lercher, Micro Meso Mater. 3 (1995) 457-465.

[37] C.V. McDaniel, P.K. Maher, Moleculae Sieves, in: R.M. Barrer (Ed.) Society of chemical Industry, London, 1968, pp. 186-195.

[38] J. H. Lunsford, J. Phys. Chem. 72 (1968) 4163-4168. 
[39] J. Abbot, Appl. Catal. 57 (1990) 105-125.

[40] V. L. Zholobenko., L. M. Kustov, L. E. Kazansky,.U. Lohse, G. Oehlmann, Zeolites. 11 (1991) 132-134.

[42] R. Gounder, A. J. Jones, R. T. Carr, E. Iglesia, J. Catal., 286 (2012) 214.

[43] C. Miranda, J. Urresta, H. Cruchade, A. Tran, M. bengahlem, A. Astafan, P. gaudin, T. J. Daou, A. Ramirez, Y. pouilloux, A. Sachse, L. pinard, J. Catal. 365 (2018) 249-260.

[44] M. Guisnet, P. Magnoux, D. Martin, D. Stud. Surf. Sci. Catal. 111 (1997) 1-19.

[45] F. Ngoye, L. Lakiss, Z. Qin, S. Laforge, C. Canaff, M. Tarighi, V. Valtchev, K.Thomas, A. Vicente, J.-P. Gilson, Y. Pouilloux, C. Fernandez, L. Pinard, J. Catal. 320 (2014) 118-126.

[46] M. Bjørgen, F. Joensen, M.S. Holm, U. Olsbye, K.P. Lillerud, S. Svelle, Appl. Catal. A: Gen. 345 (2008) 43-50. 
Table 1: Composition of alkaline solution for desilication: regular, CTAB and pyridine assisted desilication and yield of the post-synthesis treatments.

Table 2: Operating conditions for the two model reactions used for the characterization of the acid sites (number, strength).

Table 3. Textural properties of parent zeolite (M20) and after desilication by $\mathrm{NaOH}$ (D) in the presence of CTAB (DC) or assisted by pyridine (DPc and DP); P: blank samples.

Table 4. Global $\mathrm{Si} / \mathrm{Al}$ molar ratio and number of acid sites able to retained pyridine at $150{ }^{\circ} \mathrm{C}$ and $450{ }^{\circ} \mathrm{C}$ on parent zeolite (M20) and after desilication by $\mathrm{NaOH}$ (D) in the presence of CTAB (DC) or assisted by pyridine (DPc and DP); P: blank samples.

Table 5. Initial activity $\left(\mathrm{A}_{0}\right)$, turnover frequency of acid site probed by pyridine at $150{ }^{\circ} \mathrm{C}(\mathrm{TOF})$, residual activity after $1 \mathrm{~h}$ reaction $\left(\mathrm{A}_{60} / \mathrm{A}_{0}\right)$ and coke content for $n$-hexane cracking measured by elemental analysis. $\mathrm{O} / \mathrm{P}$ molar ratio corresponds to the olefins/paraffins ratio.

Table 6. Coke uptake resulting of the propene transformation at $350{ }^{\circ} \mathrm{C}$ on the parent zeolite and the four catalysts (initial coking rate and content after $10 \mathrm{~h}$ reaction time).

Scheme 1. Schematic representation of the development of textural features and silanols during classical and pyridine assisted desilication.

Figure 1. Comparison of the nitrogen adsorption and desorption isotherms at $77 \mathrm{~K}$ of the parent mordenite (M20) and the four series: D, DC, DP and DPc.

Figure 2. TEM images of M20 and of materials from each four series: D, DC, DP and DPc.

Figure 3. Comparison of IR spectra before and after pyridine adsorption at $150{ }^{\circ} \mathrm{C}$ of M20 and the four catalyst series: D, DC, DP and DPc.

Figure 4. Conversion of $n$-hexane cracking at $540{ }^{\circ} \mathrm{C}$ as a function of time-on-stream obtained on the parent mordenite (M20) and on the four modified series.

Figure 5. Coke uptake resulting from propene transformation at $350{ }^{\circ} \mathrm{C}$ on the parent zeolite and the four catalyst series: D, DC, DP and DPc. 
Figure S1. BJH pore size distribution plots derived from the adsorption branch between M20 and the four series: D, DC, DP and DPc.

Figure S2. Pyridine content of DPc during desilication.

Figure S3. XRD patterns of the M20 and the four modified catalysts series

Figure S4. Molar yields as a function of the initial conversion for $n$-hexane cracking for the four catalysts series.

Figure S5. $\quad \mathrm{C}_{4} / \mathrm{C}_{2}$ (a) and $\mathrm{C}_{5} / \mathrm{C}_{1}$ (b) ratio as a function of the initial conversion for all catalysts in $n$-hexane cracking.

Figure S6. Conversion as a function of time-on-stream obtained at different contact time (0.01, 0.02 and 0.04$)$ on $\mathrm{D}_{0.6} \mathrm{P}_{1650}$. 
Table 1. Composition of alkaline solution for desilication: regular, CTAB and pyridine assisted desilication and yield of the post-synthesis treatments.

\begin{tabular}{|c|c|c|c|c|c|}
\hline \multirow[t]{2}{*}{ Series } & \multirow[t]{2}{*}{ Catalyst } & {$[\mathrm{NaOH}]$} & [CTAB] & \multirow{2}{*}{$\begin{array}{c}\text { [Pyridine] } \\
\mu \mathrm{mol} / \mathrm{g}_{\text {zeolite }}\end{array}$} & \multirow{2}{*}{$\begin{array}{c}\text { Yield }^{\mathrm{a}} \\
(\%)\end{array}$} \\
\hline & & \multicolumn{2}{|c|}{ (M) } & & \\
\hline \multirow{2}{*}{ D (Regular) } & $\mathrm{D}_{0.2}$ & 0.2 & & & 73 \\
\hline & $\mathbf{D}_{0.6}$ & 0.6 & & & 66 \\
\hline \multirow{2}{*}{ DC (with CTAB) } & $\mathbf{D}_{0.2} \mathrm{C}$ & 0.2 & 0.27 & & 76 \\
\hline & $\mathbf{D}_{0.6} \mathrm{C}$ & 0.6 & 0.27 & & 61 \\
\hline DPc (with chemisorbed pyridine) & $\mathbf{D}_{0.6} \mathbf{P}_{550}$ & 0.6 & & 550 & 68 \\
\hline \multirow{3}{*}{ DP (with excess of pyridine) } & $\mathbf{D}_{0.6} \mathbf{P}_{1650}$ & 0.6 & & 1650 & 77 \\
\hline & $D_{0.6} P_{8250}$ & 0.6 & & 8250 & 76 \\
\hline & $\mathbf{D}_{0.6} \mathbf{P}_{16500}$ & 0.6 & & 16500 & 72 \\
\hline \multirow{2}{*}{$\mathbf{P}$ (blank) } & $\mathbf{P}_{8250}$ & & & 8250 & 91 \\
\hline & $\mathbf{P}_{550}$ & & & 550 & 88 \\
\hline
\end{tabular}

${ }^{a}$ Calculated from the weight before and after post-treatment. 
Table 2. Operating conditions for the three model reactions used for the characterization of the acid sites (number, strength, location, ...).

\begin{tabular}{l|cc}
\hline & $\begin{array}{c}\text { n-hexane cracking } \\
\text { Propene transformation } \\
\text { (Coking) }\end{array}$ & $\begin{array}{c}\text { Microbalance } \\
\text { Pretreatment }\end{array}$ \\
\hline Reaction temperature $\left({ }^{\circ} \mathbf{C}\right)$ & $540^{\circ} \mathrm{C}, 8 \mathrm{~h}, \mathrm{~N}_{2}$ & $350^{\circ} \mathrm{C}, 10 \mathrm{~h}$, primary vacuum \\
Pressure (MPa) & 540 & 350 \\
Molar ratio & 0.1 & 0.01 \\
Contact time (s) & $\mathrm{N}_{2} / n-\mathrm{C}_{6}=9$ & $/$ \\
Reaction time (h) & 0.04 & $\infty$ \\
\hline
\end{tabular}


Table 3. Textural properties of parent zeolite (M20) and after desilication by $\mathrm{NaOH}$ (D) in the presence of CTAB (DC) or assisted by pyridine (DPc and DP); P: blank samples.

\begin{tabular}{|c|c|c|c|c|c|c|}
\hline Series & Catalyst & $\begin{array}{c}\text { Crystallinity }^{\mathrm{a}} \\
(\%)\end{array}$ & $\begin{array}{l}\mathbf{C C S}^{\mathbf{b}} \\
(\mathrm{nm})\end{array}$ & Strain $^{\mathrm{c}}$ & $\begin{array}{r}V_{\text {micro }} \\
\text { (cr }\end{array}$ & $\begin{array}{l}V_{\text {meso }}^{e} \\
\text { 1) }\end{array}$ \\
\hline $\mathbf{M}$ & M20 & 100 & 66.4 & 7.3 & 0.18 & 0.11 \\
\hline \multirow{2}{*}{ D } & $D_{0.2}$ & 93 & 55.7 & 9.1 & 0.16 & 0.13 \\
\hline & $D_{0.6}$ & 60 & 56.3 & 8.9 & 0.09 & 0.54 \\
\hline \multirow{2}{*}{ DC } & $\mathrm{D}_{0.2} \mathrm{C}$ & 98 & 57.8 & 8.2 & 0.18 & 0.15 \\
\hline & $\mathrm{D}_{0.6} \mathrm{C}$ & 68 & 48.7 & 10.5 & 0.09 & 0.36 \\
\hline DPc & $\mathbf{D}_{0.6} \mathbf{P}_{550}$ & 67 & 48.6 & 10.9 & 0.09 & 0.66 \\
\hline \multirow{3}{*}{ DP } & $D_{0.6} P_{1650}$ & 66 & 55.8 & 9.8 & 0.08 & 0.58 \\
\hline & $D_{0.6} P_{8250}$ & 59 & 58.1 & 9.9 & 0.10 & 0.72 \\
\hline & $\mathbf{D}_{0.6} \mathbf{P}_{16500}$ & 42 & 58.7 & 9.8 & 0.11 & 0.54 \\
\hline \multirow{2}{*}{$\mathbf{P}$} & $\mathbf{P}_{\mathbf{8 2 5 0}}$ & 92 & 55.4 & 9.6 & 0.16 & 0.11 \\
\hline & $P_{550}$ & 87 & 53.6 & 9.6 & 0.16 & 0.13 \\
\hline
\end{tabular}

${ }^{d}$ Estimated by $t$-plot method; ${ }^{e}$ Mesopore volume $=V_{\text {total }}-V_{\text {micro }}\left(V_{\text {total }}\right.$ : determined from the adsorbed volume at $\left.P / P_{0}=0.96\right)$. 
Table 4. Global Si/Al molar ratio and number of acid sites able to retained pyridine at $150{ }^{\circ} \mathrm{C}$ and $450{ }^{\circ} \mathrm{C}$ on parent zeolite (M20) and after desilication by $\mathrm{NaOH}$ (D) in the presence of CTAB (DC) or assisted by pyridine (DPc and DP); P: blank samples.

\begin{tabular}{|c|c|c|c|c|c|c|}
\hline \multirow[t]{3}{*}{ Series } & \multirow[t]{3}{*}{ Catalyst } & \multirow{3}{*}{$\begin{array}{c}\mathrm{Si} / \mathrm{Al}^{\mathrm{a}} \\
\mathrm{mol} / \mathrm{mol}\end{array}$} & \multicolumn{2}{|c|}{$\left[\mathbf{H}^{+}\right]^{\mathbf{b}}$} & {$[\mathbf{L}]^{\mathrm{c}}$} & \multirow{3}{*}{$\begin{array}{c}\text { Accessibility }^{\mathrm{d}} \\
\%\end{array}$} \\
\hline & & & $150{ }^{\circ} \mathrm{C}$ & $450{ }^{\circ} \mathrm{C}$ & $150{ }^{\circ} \mathrm{C}$ & \\
\hline & & & \multicolumn{3}{|c|}{$\mu \mathrm{mol} \mathrm{g} \mathrm{g}^{-1}$} & \\
\hline $\mathbf{M}$ & M20 & 20.4 & 552 & 109 & 47 & 100 \\
\hline \multirow{2}{*}{ D } & $\mathrm{D}_{0.2}$ & 18.2 & $491(515)$ & 44 & 96 & 95 \\
\hline & $D_{0.6}$ & 17.1 & $324(431)$ & 15 & 40 & 67 \\
\hline \multirow{2}{*}{ DC } & $D_{0.2} C$ & 18.6 & 531 & 29 & 77 & 100 \\
\hline & $\mathrm{D}_{0.6} \mathrm{C}$ & 18.4 & $329(381)$ & 59 & 59 & 84 \\
\hline DPc & $D_{0.6} P_{550}$ & 19.5 & 328 & 79 & 90 & 100 \\
\hline \multirow{3}{*}{ DP } & $\mathbf{D}_{0.6} \mathbf{P}_{1650}$ & 17.8 & 376 & 15 & 105 & 100 \\
\hline & $\mathbf{D}_{0.6} \mathbf{P}_{8250}$ & 18.6 & 300 & 13 & 87 & 100 \\
\hline & $\mathbf{D}_{0.6} \mathbf{P}_{\mathbf{1 6 5 0 0}}$ & 18.3 & 314 & 22 & 105 & 100 \\
\hline \multirow{2}{*}{$\mathbf{P}$} & $\mathbf{P}_{8250}$ & 18.6 & 338 & 36 & 171 & 100 \\
\hline & $\mathbf{P}_{550}$ & 17.5 & 368 & 88 & 86 & 100 \\
\hline
\end{tabular}

${ }^{\circ} \mathrm{C} ;{ }^{d}$ Measured by the intensity of the hydroxyl group before and after the adsorption of pyridine at $150{ }^{\circ} \mathrm{C} .{ }^{*}$ Between brackets are the expected acidity. 
Table 5. Initial activity $\left(\mathrm{A}_{0}\right)$, turnover frequency of acid site probed by pyridine at $150{ }^{\circ} \mathrm{C}$ (TOF), residual activity after $1 \mathrm{~h}$ reaction $\left(\mathrm{A}_{60} / \mathrm{A}_{0}\right)$ and coke content for $n$-hexane cracking measured by elemental analysis. O/P molar ratio corresponds to the olefins/paraffins ratio.

\begin{tabular}{c|l|c|c|c|c|c|c}
\hline Series & Catalyst & $\begin{array}{c}\mathbf{A}_{\mathbf{0}} \\
\mathbf{m m o l ~ h}^{\mathbf{- 1}} \mathbf{g}^{-\mathbf{1}}\end{array}$ & $\begin{array}{c}\mathbf{T O F} \\
\mathbf{h}^{\mathbf{- 1}}\end{array}$ & $\begin{array}{c}\mathbf{O} / \mathbf{P} \\
\mathbf{m o l} / \mathbf{m o l}\end{array}$ & $\begin{array}{c}\mathbf{i} / \mathbf{n} \\
\mathbf{m o l} / \mathbf{m o l}\end{array}$ & $\begin{array}{c}\mathbf{A}_{\mathbf{6 0}} \\
\mathbf{m m o l ~ \mathbf { h } ^ { - 1 }} \mathbf{g}^{-\mathbf{1}}\end{array}$ & $\begin{array}{c}\text { Coke } \\
\mathbf{\%}\end{array}$ \\
\hline $\mathbf{M}$ & $\mathbf{M 2 0}$ & 72 & 131 & 0.95 & 1.35 & $62(-14 \%)$ & 0.5 \\
\hline \multirow{2}{*}{$\mathbf{D}$} & $\mathbf{D}_{\mathbf{0 . 2}}$ & 101 & $206(196)^{*}$ & 1.26 & 1.29 & $61(-39 \%)$ & - \\
& $\mathbf{D}_{\mathbf{0 . 6}}$ & 99 & $304(229)$ & 1.46 & 1.64 & $40(-59 \%)$ & 1.8 \\
\hline \multirow{2}{*}{$\mathbf{D C}$} & $\mathbf{D}_{\mathbf{0 . 2}} \mathbf{C}$ & 66 & 124 & 1.38 & 1.54 & $23(-65 \%)$ & 5.2 \\
& $\mathbf{D}_{\mathbf{0 . 6}} \mathbf{C}$ & 69 & $208(180)$ & 1.41 & 1.68 & $35(-48 \%)$ & 3.2 \\
\hline $\mathbf{D P c}$ & $\mathbf{D P}_{\mathbf{5 5 0}}$ & 165 & 503 & 1.35 & 1.78 & $84(-49 \%)$ & 2.5 \\
\hline \multirow{2}{*}{$\mathbf{D P}$} & $\mathbf{D}_{\mathbf{0 . 6}} \mathbf{P}_{\mathbf{1 6 5 0}}$ & 249 & 663 & 1.34 & 1.81 & $64(-74 \%)$ & 2.8 \\
& $\mathbf{D}_{\mathbf{0 . 6}} \mathbf{P}_{\mathbf{8 2 5 0}}$ & 217 & 722 & 1.52 & 1.86 & $58(-63 \%)$ & 2.5 \\
& $\mathbf{D}_{\mathbf{0 . 6}} \mathbf{P}_{\mathbf{1 6 5 0 0}}$ & 201 & 641 & 1.18 & 1.68 & $74(-63 \%)$ & 1.8 \\
\hline \multirow{2}{*}{$\mathbf{P}$} & $\mathbf{P}_{\mathbf{8 2 5 0}}$ & 102 & 301 & 1.73 & 1.94 & $34(-66 \%)$ & - \\
& $\mathbf{P}_{\mathbf{5 5 0}}$ & 106 & 287 & 1.49 & 1.91 & $47(-55 \%)$ & - \\
\hline
\end{tabular}

*Between brackets are the expected TOF values w.r.t the expected acidity. 
Table 6. Coke uptake resulting of the propene transformation at $350{ }^{\circ} \mathrm{C}$ on the parent zeolite and the four catalysts (initial coking rate and content after $10 \mathrm{~h}$ reaction time).

\begin{tabular}{c|l|c|c}
\hline Series & Catalyst & $\begin{array}{c}\text { Rate } \\
\mathbf{h}^{-\mathbf{1}}\end{array}$ & $\begin{array}{c}\text { Coke } \\
\mathbf{\%}\end{array}$ \\
\hline $\mathbf{M}$ & $\mathbf{M 2 0}$ & 71 & 8.6 \\
\hline $\mathbf{D}$ & $\mathbf{D}_{\mathbf{0 . 6}}$ & 143 & 12.6 \\
\hline $\mathbf{D C}$ & $\mathbf{D}_{\mathbf{0 . 6}} \mathbf{C}$ & 139 & 12.4 \\
\hline $\mathbf{D P}$ & $\mathbf{D}_{\mathbf{0 . 6}} \mathbf{P}_{\mathbf{1 6 5 0}}$ & 157 & 11.2 \\
& $\mathbf{D}_{\mathbf{0 . 6}} \mathbf{P}_{\mathbf{8 2 5 0}}$ & 150 & 11.1 \\
\hline $\mathbf{D P c}$ & $\mathbf{D}_{\mathbf{0 . 6}} \mathbf{P}_{\mathbf{5 5 0}}$ & 126 & 10.6 \\
\hline
\end{tabular}




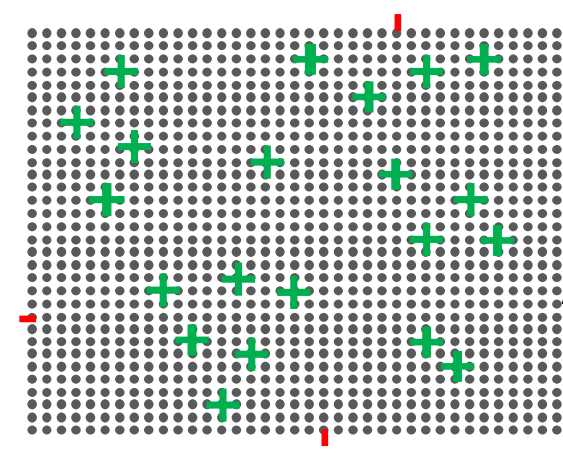

Classical desilication
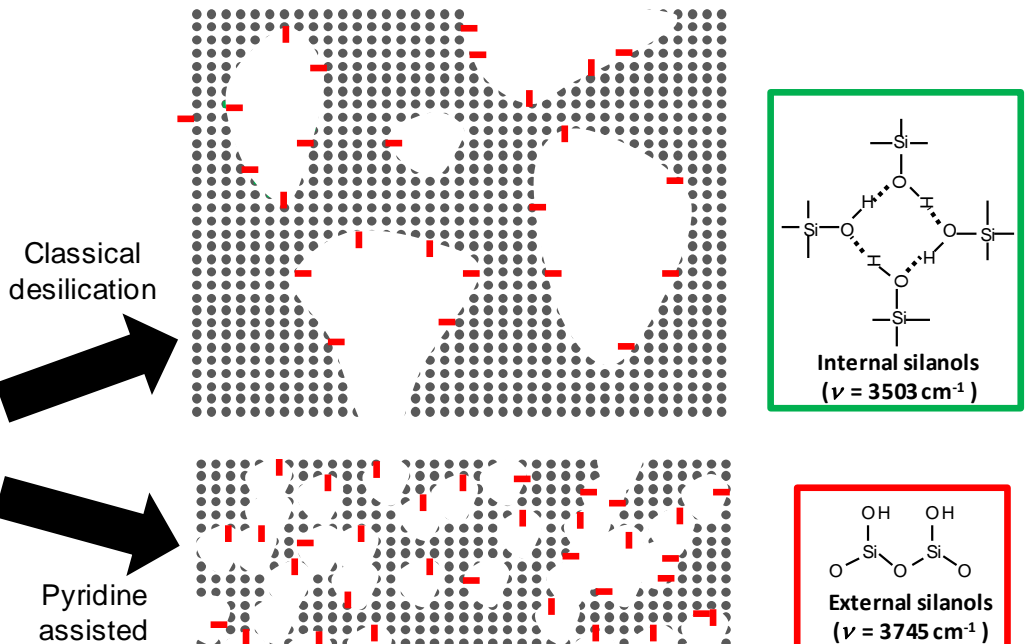

desilication
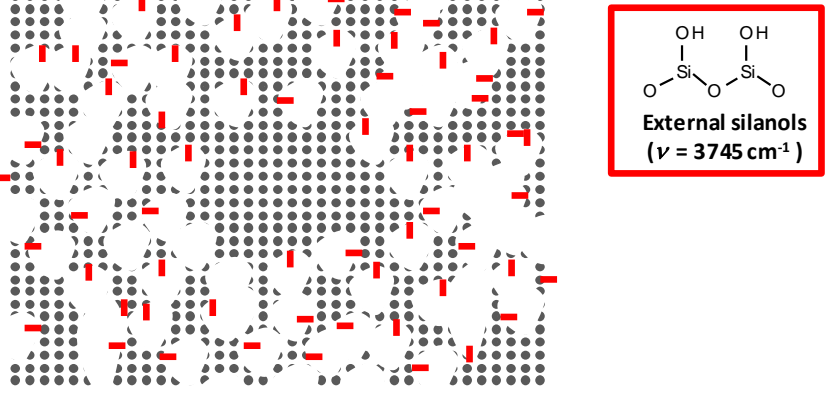

Scheme 1. Schematic representation of the development of textural features and silanols during classical and pyridine assisted desilication. 
D
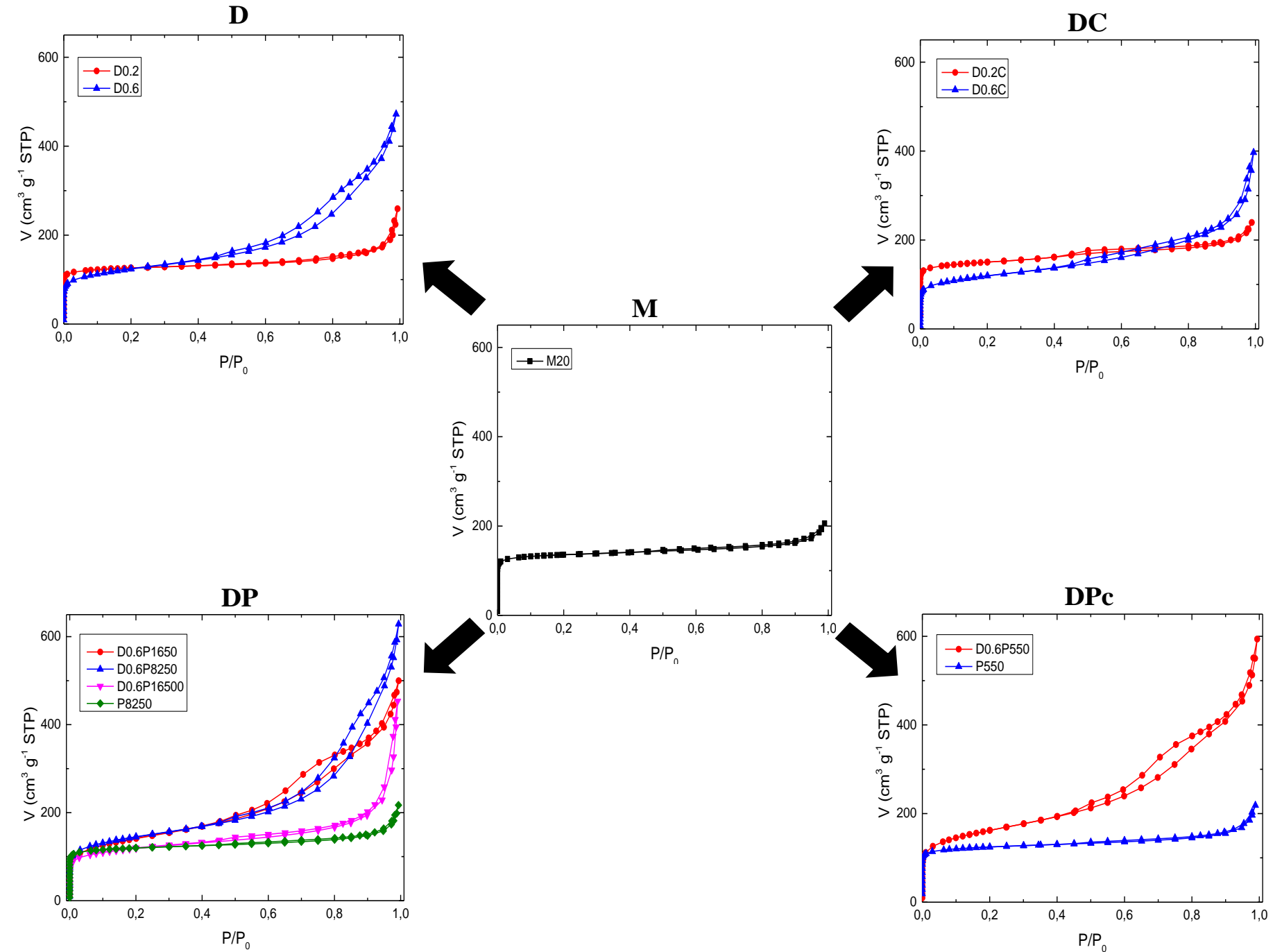

Figure 1. Comparison of the nitrogen adsorption and desorption isotherms at $77 \mathrm{~K}$ of the parent mordenite (M20) and the four series: D, DC, DP and DPc. 
D

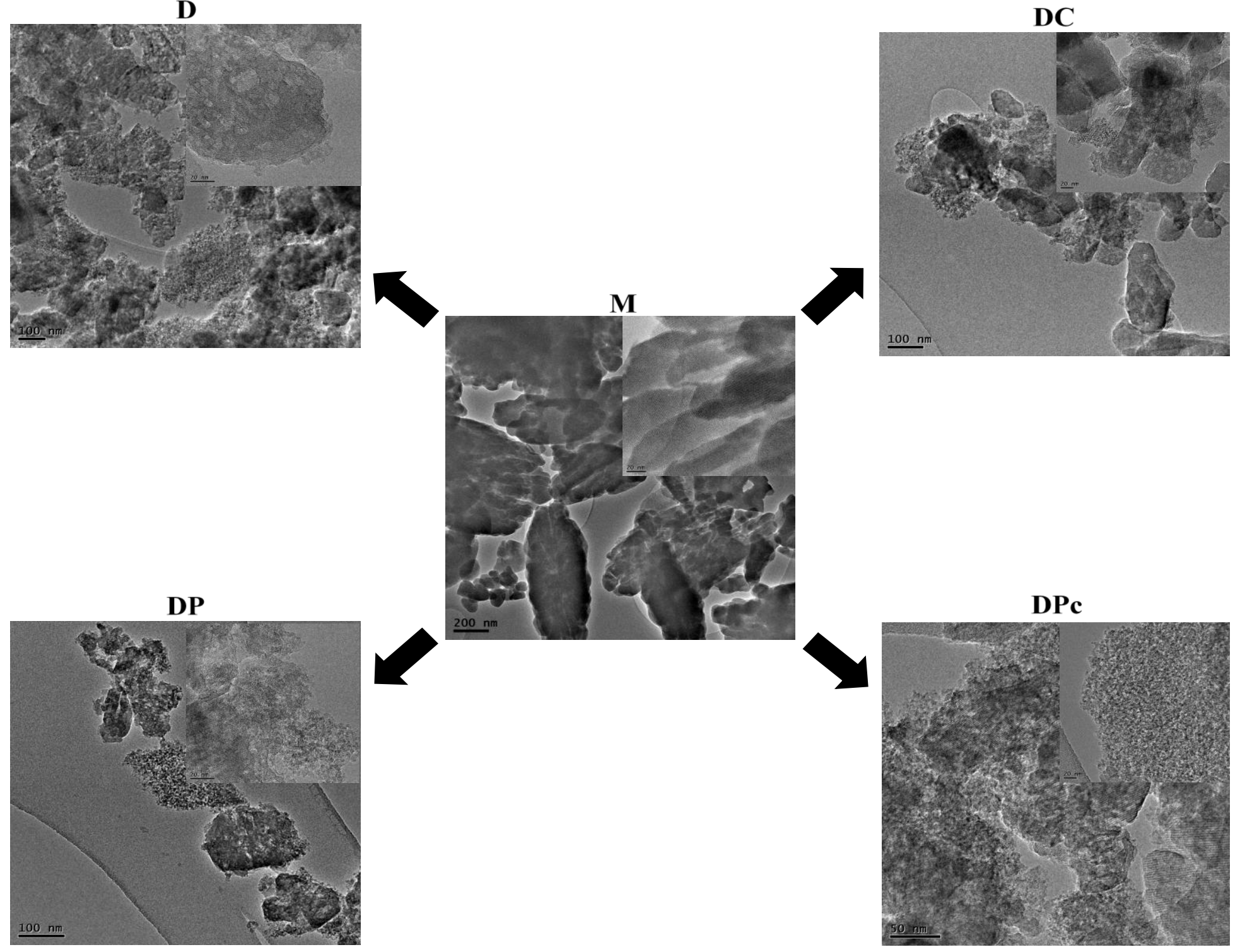

Figure 2. TEM images of M20 and of materials from each four series: D, DC, DP and DPc. 
D
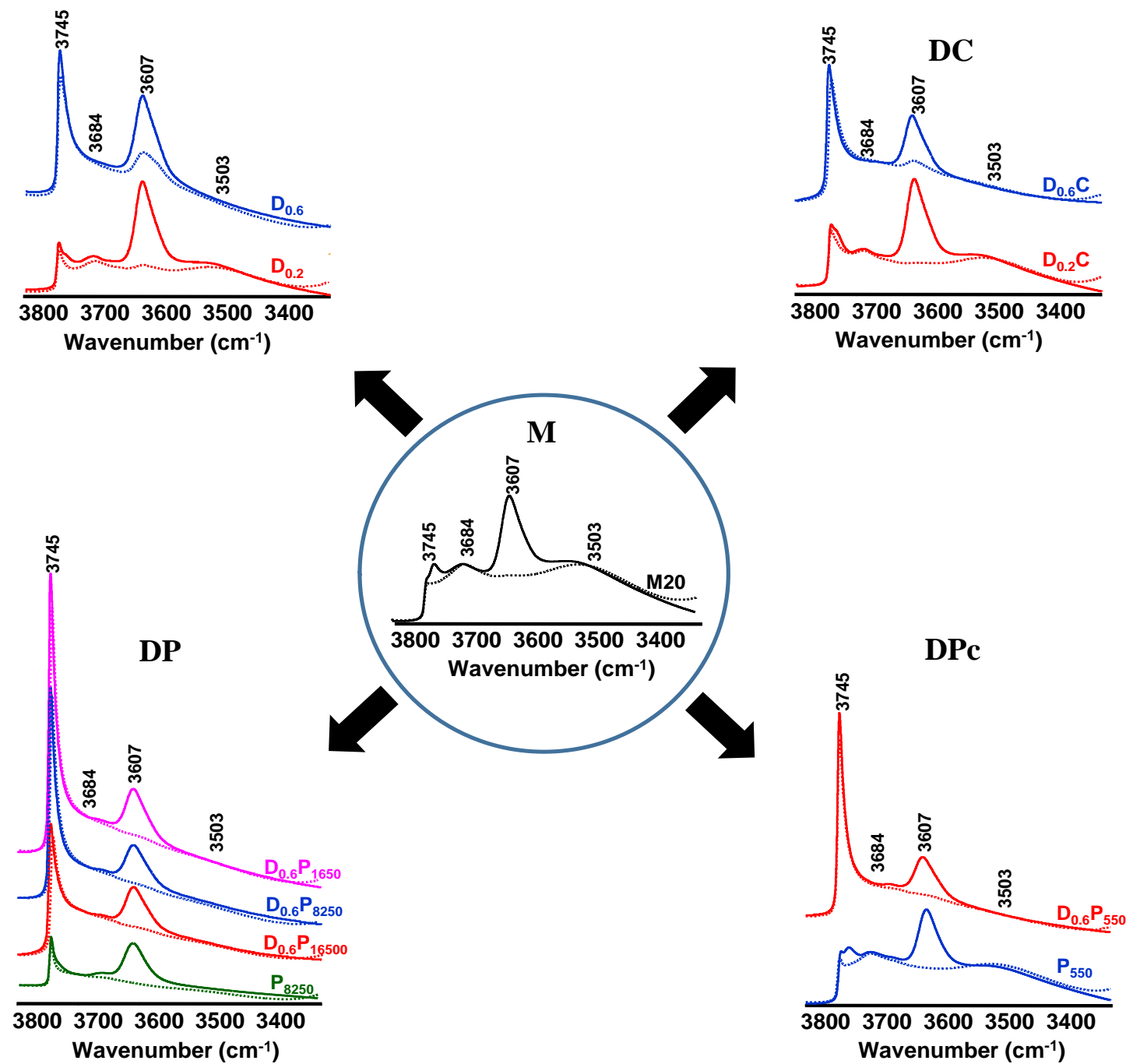

Figure 3: Comparison of IR spectra before and after pyridine adsorption at $150{ }^{\circ} \mathrm{C}$ of $\mathrm{M} 20$ and the four catalyst series: D, DC, DP and DPc. 


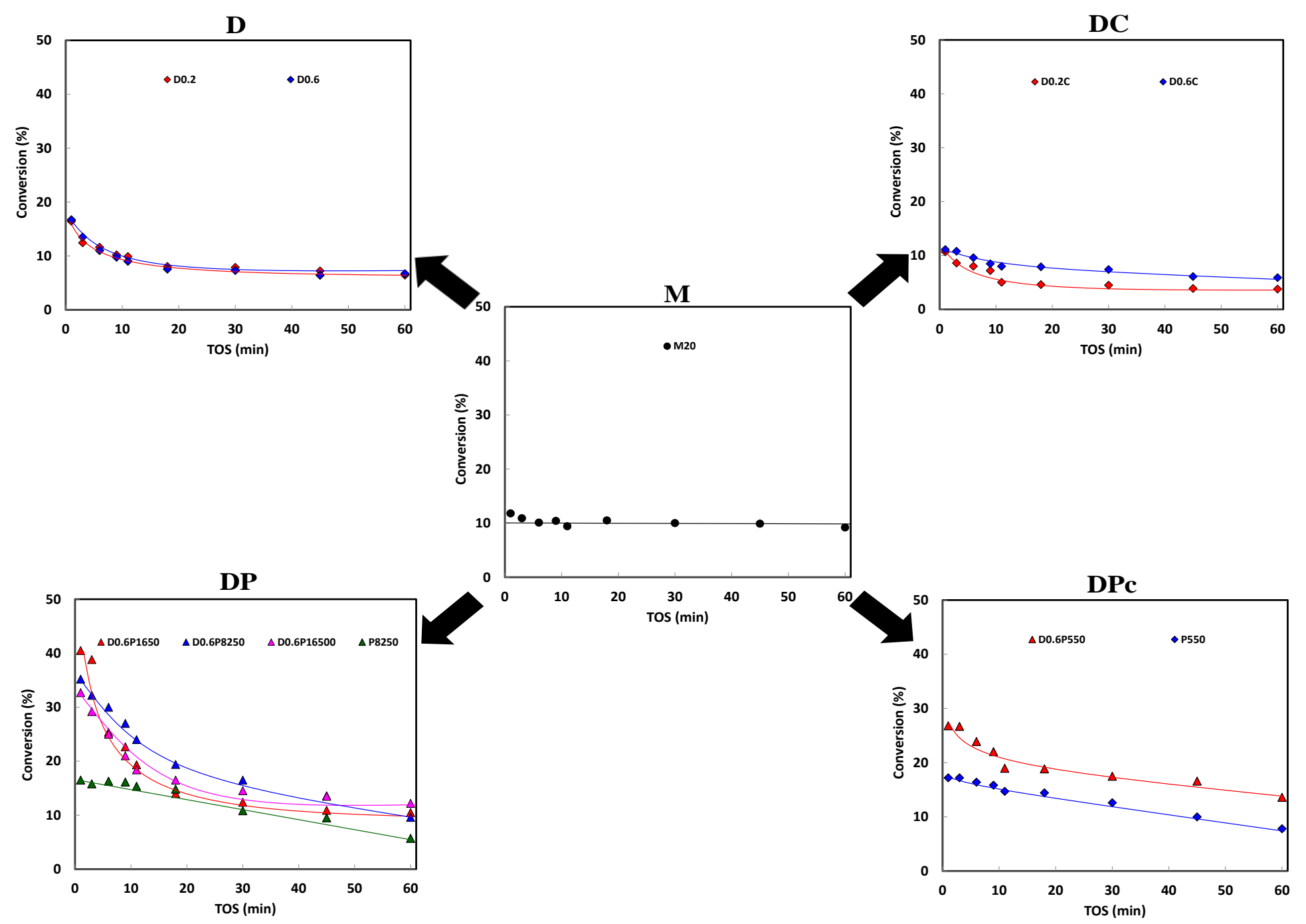

Figure 4. Conversion of $n$-hexane cracking at $540{ }^{\circ} \mathrm{C}$ as a function of time-on-stream obtained on the parent mordenite (M20) and on the four modified series. 


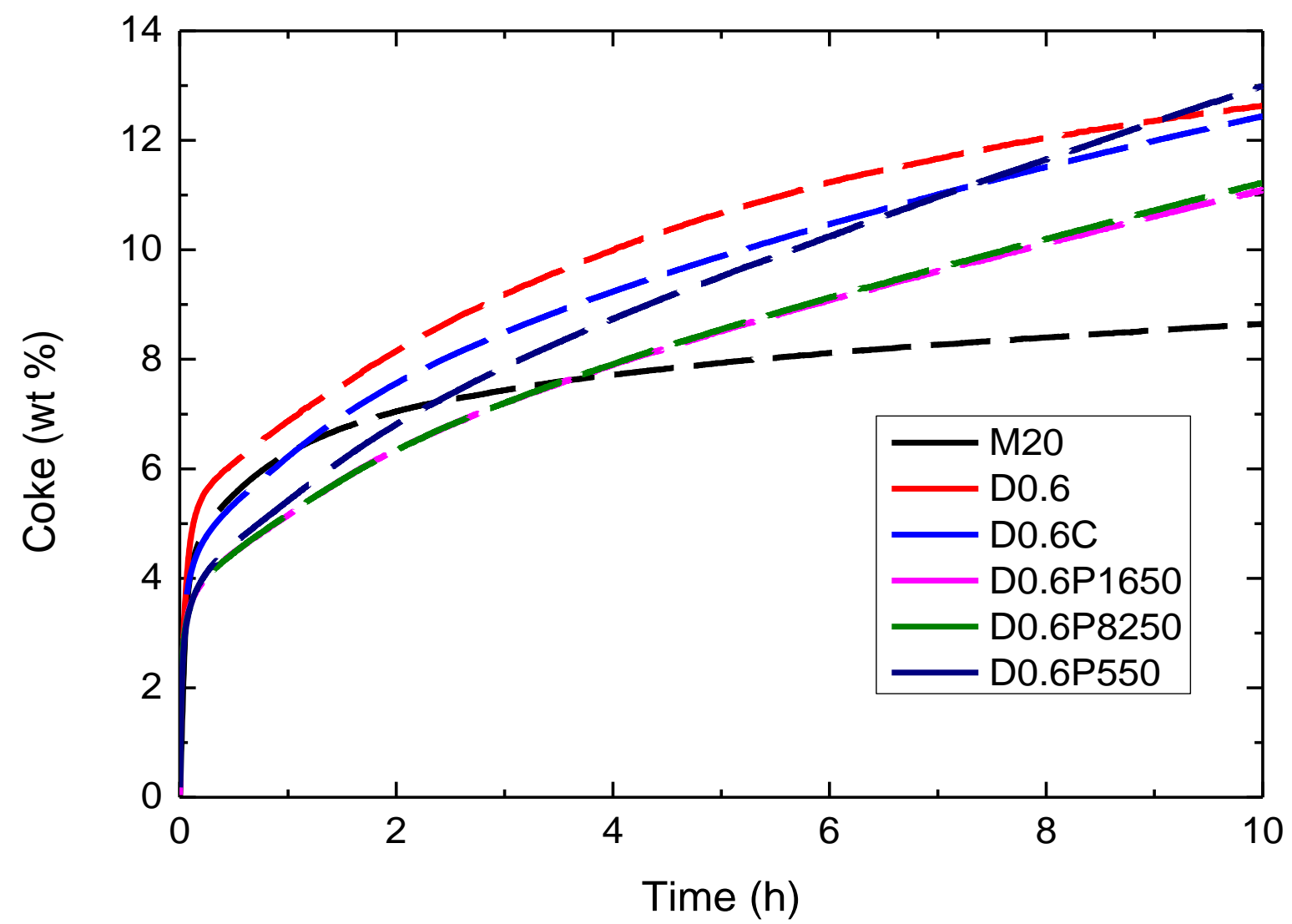

Figure 5. Coke uptake resulting from propene transformation at $350{ }^{\circ} \mathrm{C}$ on the parent zeolite and the four catalyst series: D, DC, DP and DPc. 


\section{Supporting Information}

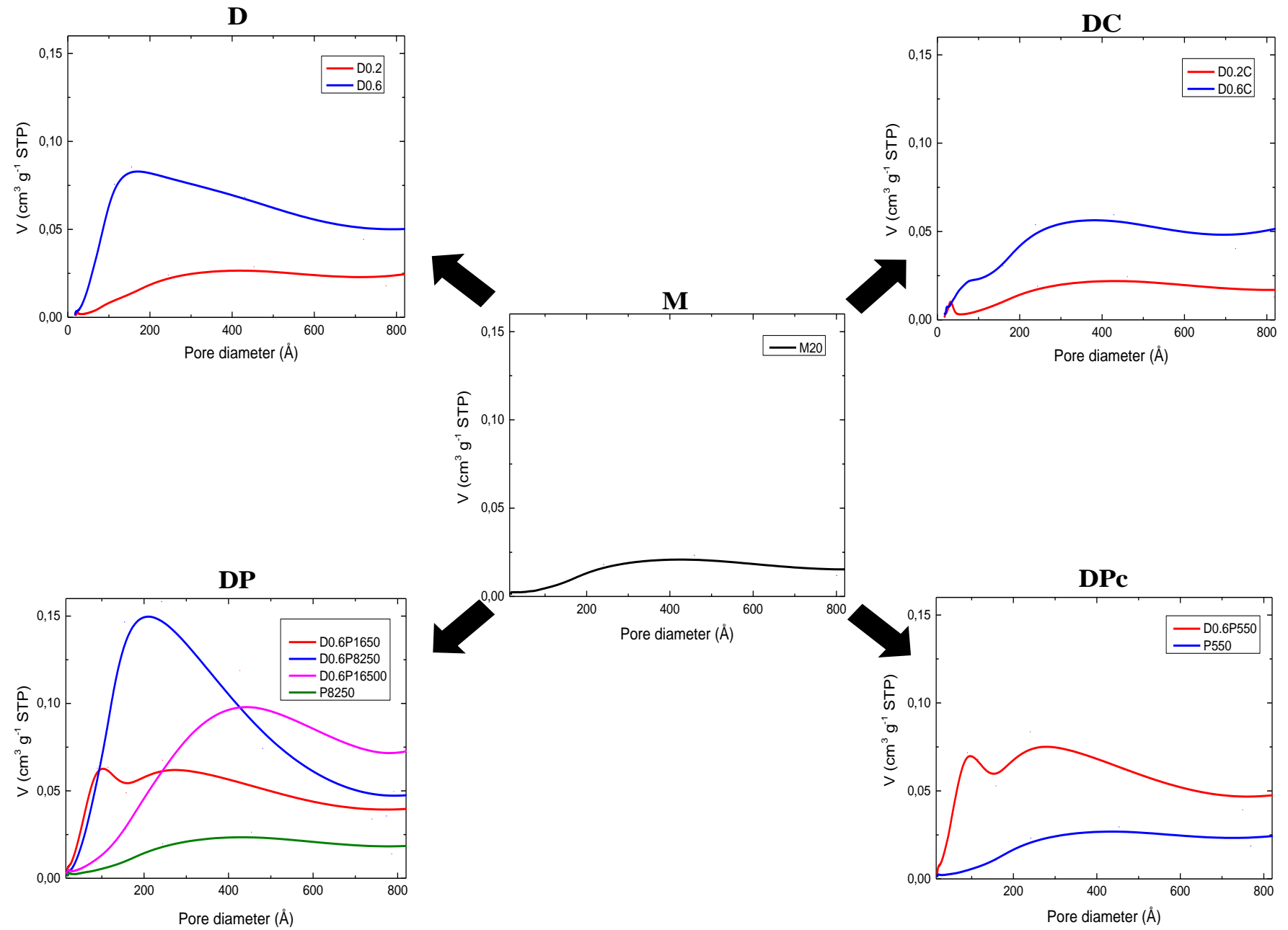

Figure S1. BJH pore size distribution plots derived from the adsorption branch for the four catalyst series: D, DC, DP and DPc. 


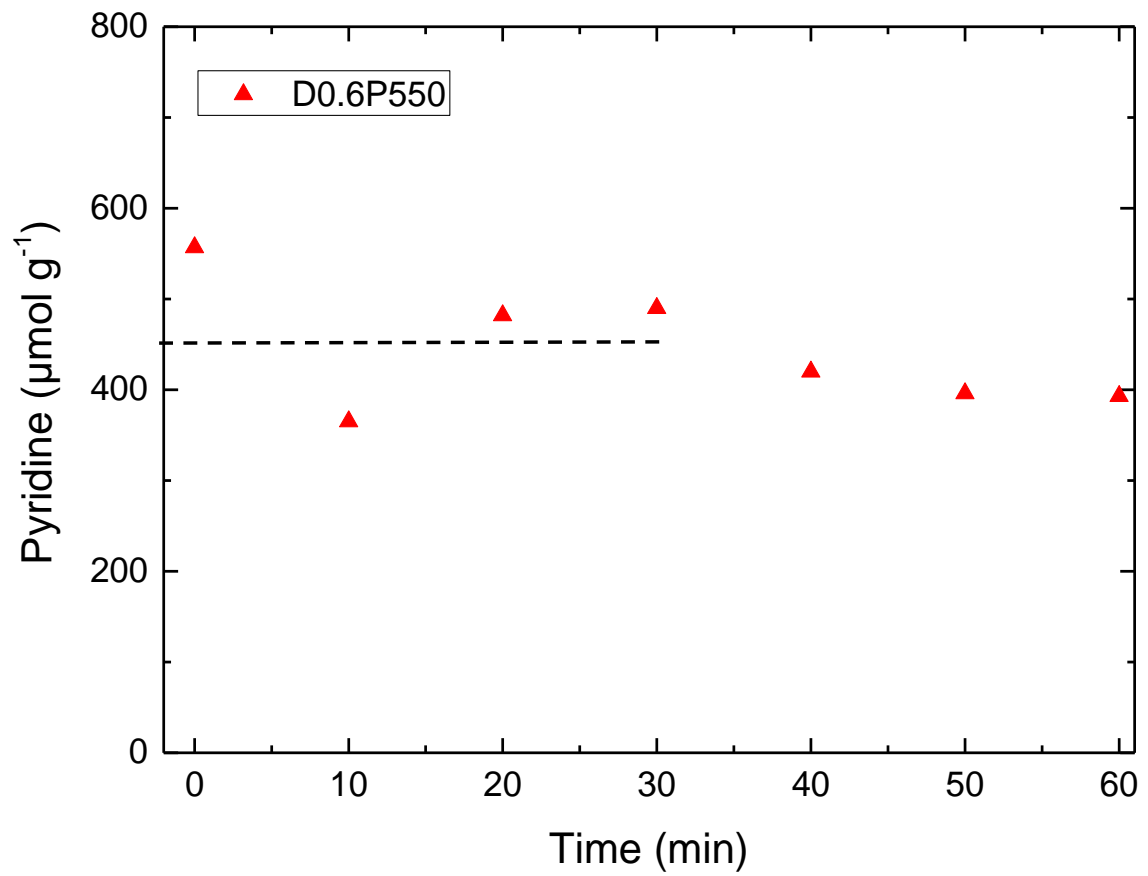

Figure S2. Pyridine content of DPc during desilication. 
D
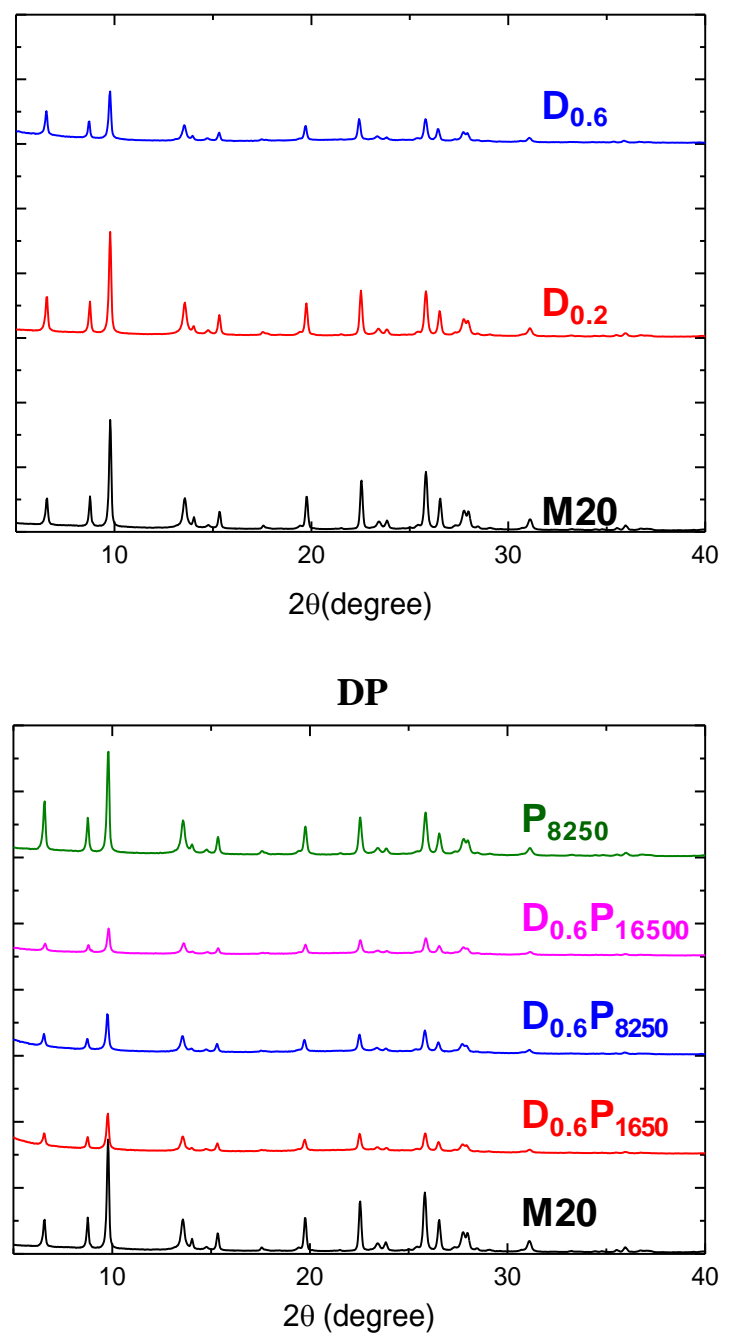

DC

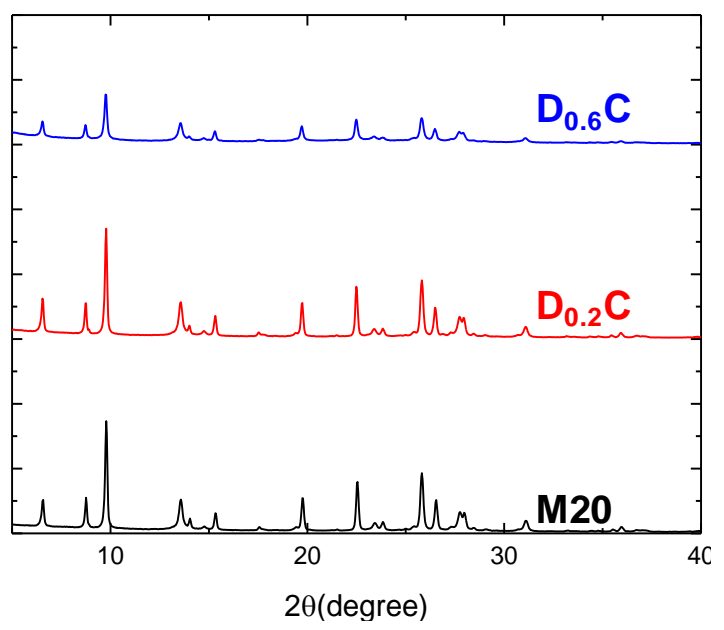

DPc

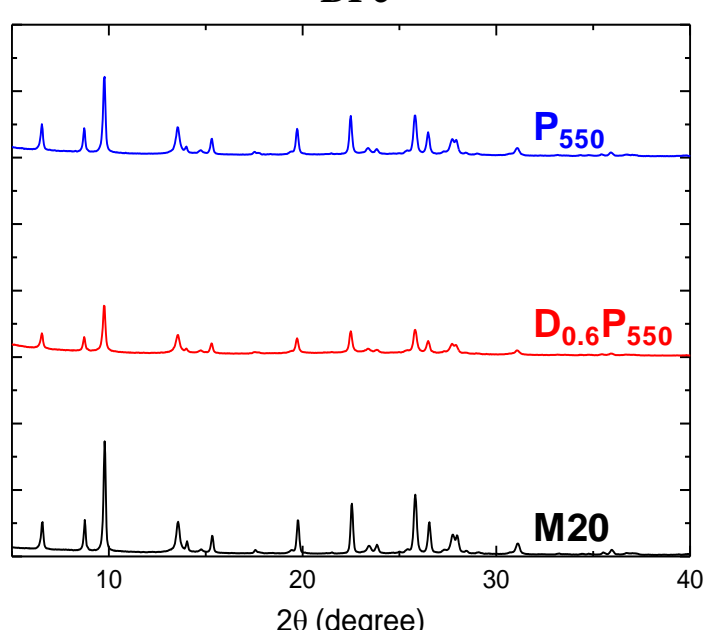

Figure S3. XRD patterns of the M20 and the four modified catalyst series. 


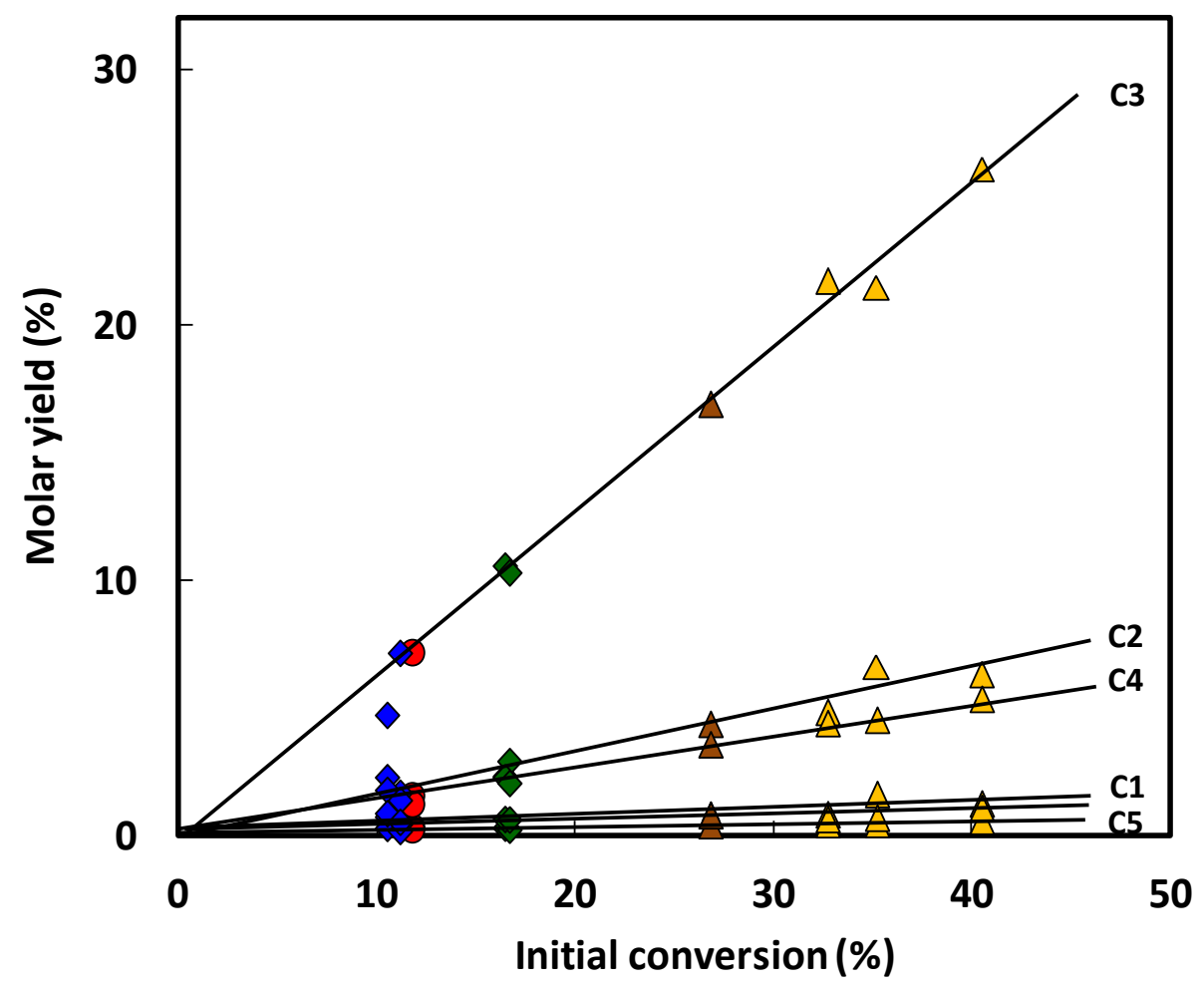

- $\mathrm{M} 20 \diamond \mathrm{D} \diamond \mathrm{DC} \triangle \mathrm{DPC} \triangle \mathrm{DP} * \mathrm{P}$

Figure S4. Molar yields as a function of the initial conversion for $n$-hexane for the four catalysts series. 

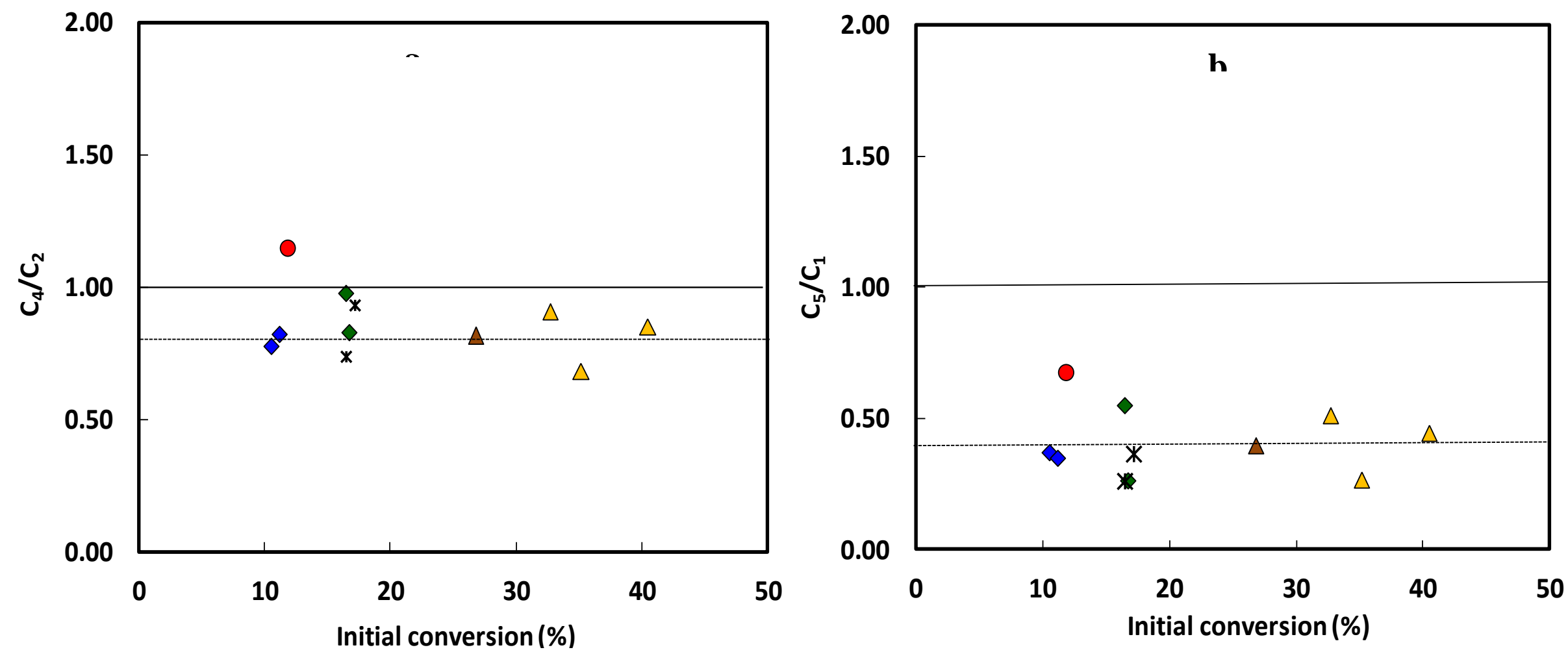

- $\mathrm{M} 20 \diamond \mathrm{D} \diamond \mathrm{DC} \triangle \mathrm{DPc} \triangle \mathrm{DP} * \mathrm{P}$

Figure S5. $\mathrm{C}_{4} / \mathrm{C}_{2}$ (a) and $\mathrm{C}_{5} / \mathrm{C}_{1}$ (b) ratio as a function of the initial conversion for all catalysts in $n$-hexane cracking. 


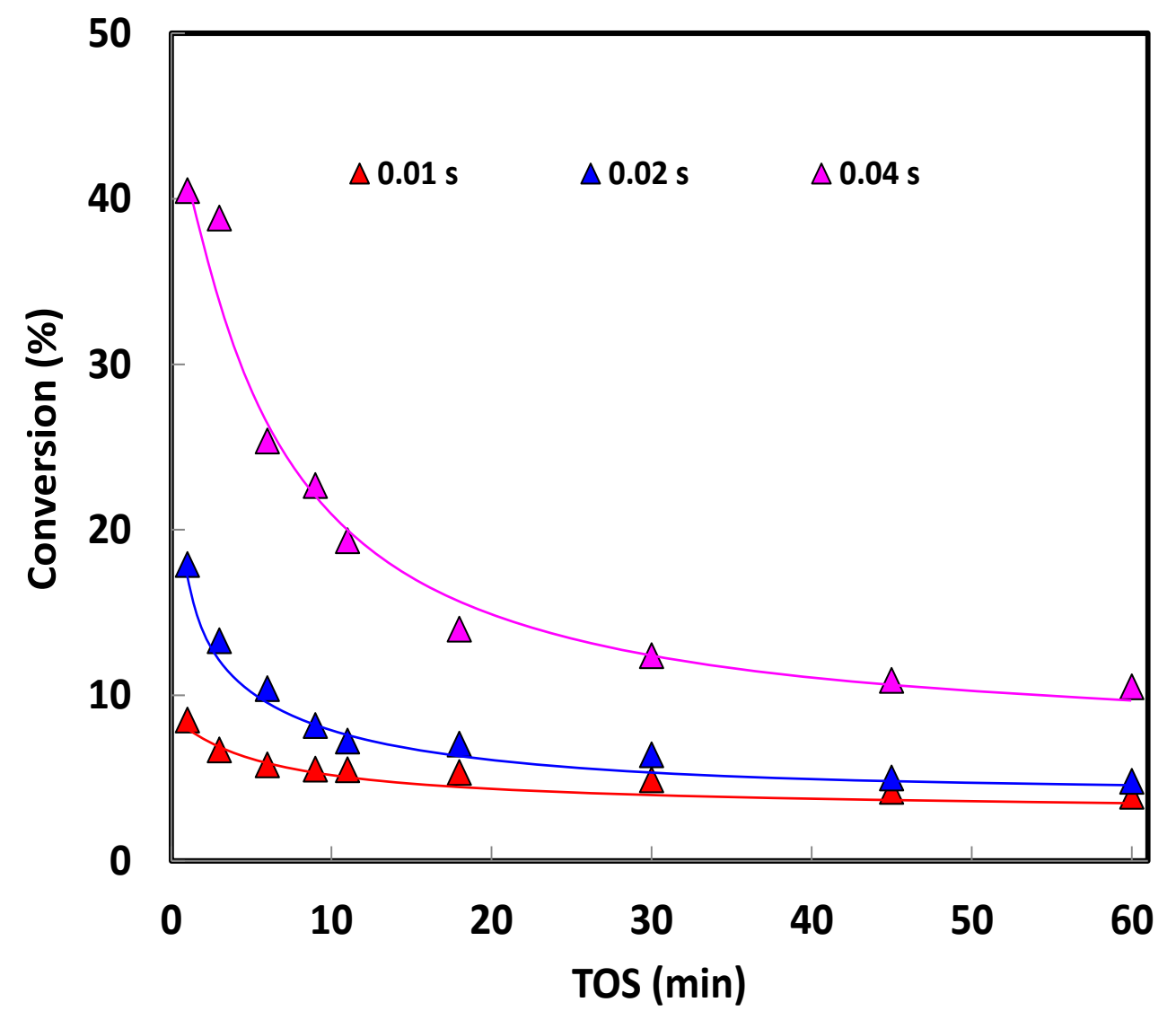

Figure S6. Conversion as a function of time-on-stream obtained at different contact time $(0.01,0.02$ and $0.04 \mathrm{~s})$ on $\mathrm{D}_{0.6} \mathrm{P}_{1650}$. 